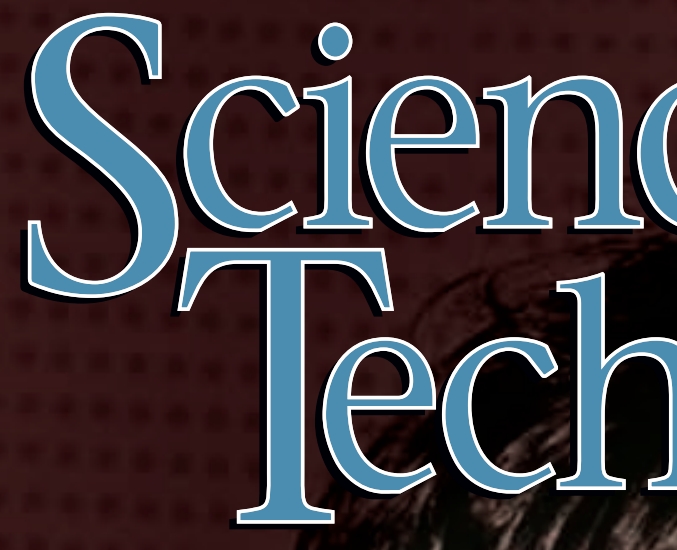

January/February 2008

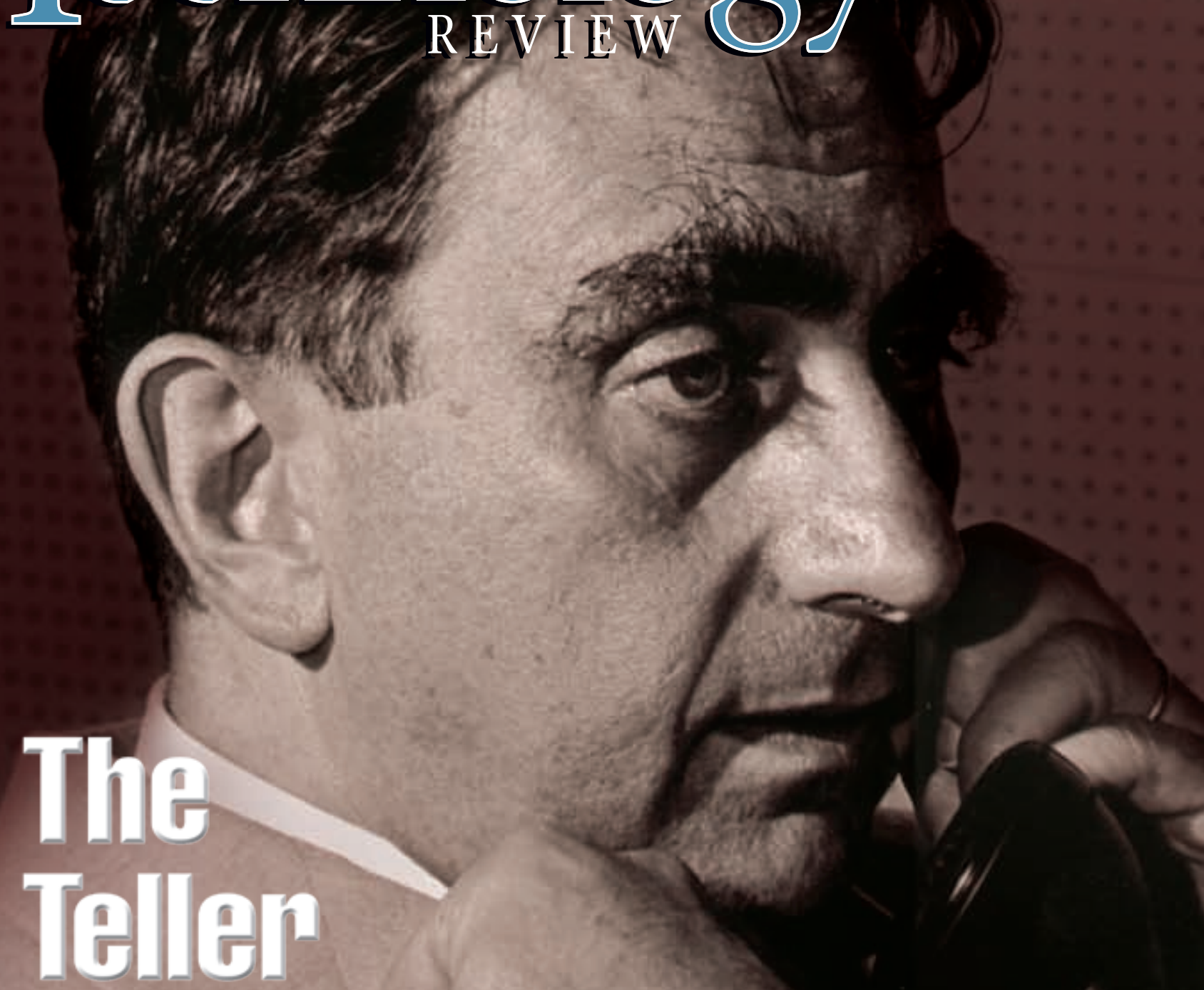

Bentuluy

Also in this issue:

- Simulating Quark Behavior

- Dentin and Fracture in Aging Teeth 


\section{About the Cover}

Lawrence Livermore cofounder Edward Teller (1908-2003) deeply influenced the 20th century in the scientific and policy arenas. On January 15, 2008, we celebrate the 100th anniversary of his birth. Teller was one of the giants of the Golden Age of Physics and an inspiration for countless researchers. For more than five decades, Teller was a major driving force behind the extraordinary record of research at Livermore. In the article beginning on p. 4, Livermore researchers remember his contributions.

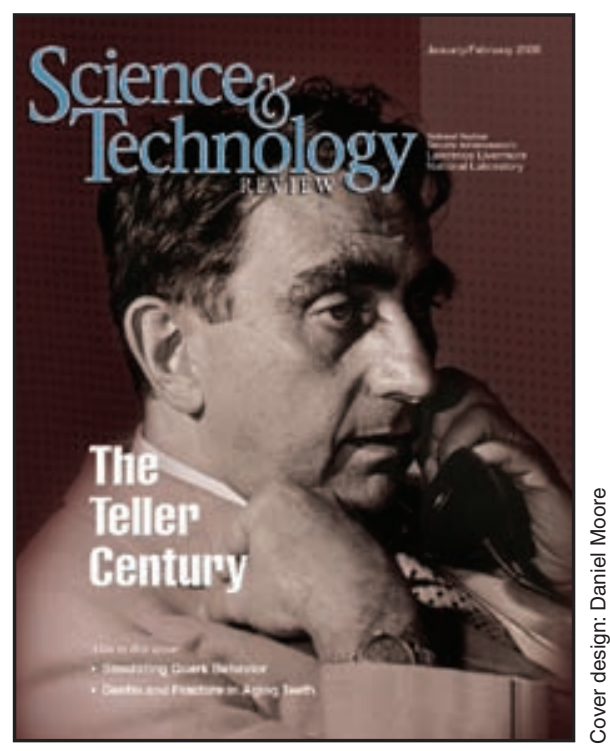

\section{About the Review}

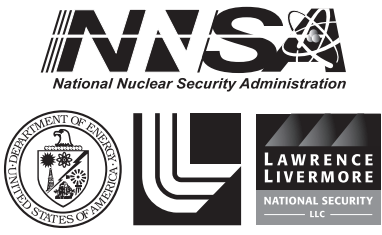

Prepared by LLNL under contract DE-AC52-07NA27344
At Lawrence Livermore National Laboratory, we focus science and technology on ensuring our nation's security. We also apply that expertise to solve other important national problems in energy, bioscience, and the environment. Science \& Technology Review is published six times a year to communicate, to a broad audience, the Laboratory's scientific and technological accomplishments in fulfilling its primary missions. The publication's goal is to help readers understand these accomplishments and appreciate their value to the individual citizen, the nation, and the world.

The Laboratory is operated by Lawrence Livermore National Security, LLC (LLNS), for the Department of Energy's National Nuclear Security Administration. LLNS is a partnership involving Bechtel National, Inc.; University of California; BWX Technologies, Inc.; Washington Group International, Inc.; and Battelle in affiliation with Texas A\&M University. More information about LLNS is available at www.llnsllc.com.

Please address any correspondence (including name and address changes) to $S \& T R$, Mail Stop L-664, Lawrence Livermore National Laboratory, P.O. Box 808, Livermore, California 94551, or telephone (925) 423-3432. Our e-mail address is str-mail@llnl.gov. $S \& T R$ is available on the Web at www.llnl.gov/str.

(C) 2008. Lawrence Livermore National Security, LLC. All rights reserved. This work was performed under the auspices of the U.S. Department of Energy by Lawrence Livermore National Laboratory under contract DE-AC52-07NA27344. To request permission to use any material contained in this document, please submit your request in writing to Library Report Orders, Lawrence Livermore National Laboratory, Mail Stop L-610, P.O. Box 808, Livermore, California 94551, or to our e-mail address str-mail@1lnl.gov.

This document was prepared as an account of work sponsored by an agency of the United States Government. Neither the United States Government nor Lawrence Livermore National Security, LLC, nor any of their employees makes any warranty, expressed or implied, or assumes any legal liability or responsibility for the accuracy, completeness, or usefulness of any information, apparatus, product, or process disclosed, or represents that its use would not infringe privately owned rights. Reference herein to any specific commercial product, process, or service by trade name, trademark, manufacturer, or otherwise, does not necessarily constitute or imply its endorsement, recommendation, or favoring by the United States Government or Lawrence Livermore National Security, LLC. The views and opinions of authors expressed herein do not necessarily state or reflect those of the United States Government or Lawrence Livermore National Security, LLC, and shall not be used for advertising or product endorsement purposes. 


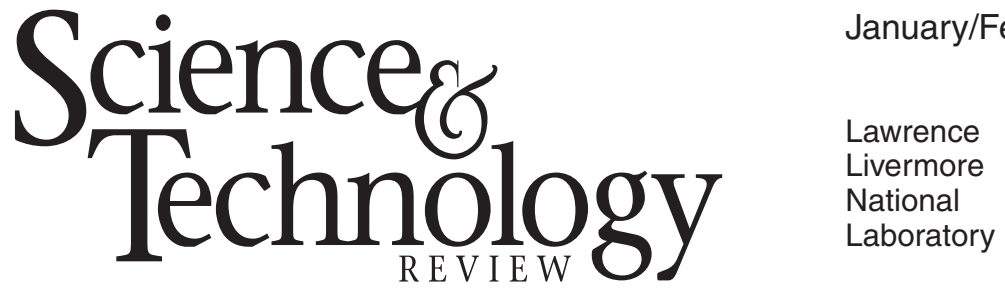

\section{S\&TR Staff}

\section{SCIENTIFIC Editor}

Diane J. Chinn

Managing Editor

Ray Marazzi

Publication Editor

Pamela MacGregor

\section{WrITERS}

Rose Hansen, Arnie Heller,

Caryn Meissner, and Katie Walter

\section{Art Director}

Daniel Moore

DESIGNERS

Amy Henke and Daniel Moore

\section{ILLUSTRATORS}

Leonard Walton

Proofreader

Carolin Middleton

Print Coordinator

Charlie M. Arteago, Jr.

$S \& T R$, a Director's Office publication, is produced by the Technical Information Department under the direction of the Office of Planning and Special Studies.

$S \& T R$ is available on the Web at www.llnl.gov/str

Printed in the United States of America

\section{Available from}

National Technical Information Service

U.S. Department of Commerce

5285 Port Royal Road

Springfield, Virginia 22161

\section{UCRL-TR-52000-08-1/2}

Distribution Category UC-99

January/February 2008

\section{Contents}

\section{Features}

3 The Edward Teller Centennial

Commentary by George H. Miller

4 Edward Teller's Century: Celebrating the Man and His Vision

Colleagues at the Laboratory remember Edward Teller - cofounder of Lawrence Livermore, adviser to U.S. presidents, and physicist extraordinaireon the 100th anniversary of his birth.

\section{Quark Theory and Today's} Supercomputers: It's a Match

Thanks to the power of BlueGene/L, Livermore has become an epicenter for theoretical advances in particle physics.

\section{Research Highlights}

\section{The Role of Dentin in Tooth Fracture}

Studies on tooth dentin show that its mechanical properties degrade with age.

\section{Departments}

2 The Laboratory in the News

20 Patents and Awards

\section{Abstracts}




\section{Spin transition in Earth's lower mantle}

Livermore researchers working in collaboration with universities and other scientific institutions have located the spin-transition zone of iron in Earth's lower mantle. Scientists determined the location by studying the electronic spin state of iron in ferropericlase (iron magnesium oxide) at high temperatures and pressures similar to those in the lower mantle. Their research appeared in the September 21, 2007, issue of Science.

The lower mantle makes up more than half Earth's volume. The spin-transition zone is the region where the electronic spin of iron in mantle minerals changes from the high- to low-spin state. In the Livermore collaboration, scientists studied the electronic spin state and crystal structure of iron in ferropericlase under lower mantle conditions using $\mathrm{x}$-ray emission spectroscopy and $\mathrm{x}$-ray diffraction with a laser-heated diamond anvil cell. Through their research, they identified the mix of iron's high- and low-spin states that is likely to occur in the spin-transition zone. The transition of iron in ferropericlase changes the material's density, elasticity, electrical conductivity, and other transport properties.

Ferropericlase is the second most abundant mineral in the lower mantle, and its physical properties are important for understanding Earth's structure and composition. By observing the spin state, scientists can better understand Earth's structure, composition, and dynamics, which affect geologic activities on the planet's surface. In addition, the techniques developed through this research will allow researchers to study how lanthanoid and actinoid compounds react under extreme pressures.

Contact: Jung-Fu Lin (925) 424-4157 (lin24@IInl.gov).

\section{Carbon nanotube interactions on the atomic scale}

Collaborators from Lawrence Livermore and several other institutions have demonstrated how carbon nanotubes interact with chemical functional groups on the atomic scale. The researchers used chemical force microscopy, a nanoscale technique for determining interaction forces, to measure for the first time a specific interaction between a single functional group and a nanotube.

Functional groups are the smallest specific collection of atoms within a molecule that control the molecule's characteristic chemical reactions. The study results, which appeared in the November 2007 edition of Nature Nanotechnology, indicate that interaction strength does not follow conventional trends of water repulsion or increased polarity, but rather depends on the intricate electronic interactions between the nanotube and the functional group. Because nanotubes are so small, researchers previously have relied on modeling, indirect measurements, and microscale tests to measure the adhesion force of an individual molecule at the carbon nanotube surface. The Livermore team achieved a more exact measurement by reducing the size of the probe-nanotube contact area.

The team then collaborated with computational chemists to simulate the functional group-nanotube interactions. Calculated interaction forces provided an exact match to experimental results. According to Livermore researcher Aleksandr Noy, "In the past, there was a gap between what we could measure in an experiment and what the computational methods could do. It is exciting to be able to bridge that gap." The ability to measure interactions on a single functional group level could allow for more accurate and precise designs of new nanocomposite materials, nanosensors, and molecular assemblies.

Contact: Aleksandr Noy (925) 424-6203 (noy1@IInl.gov). 


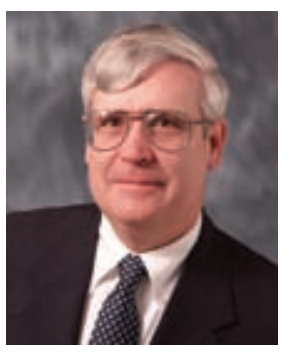

\section{The Edward Teller Centennial}

$\mathbf{E}_{\mathrm{m}}^{\mathrm{p}}$ DWARD Teller, whose centennial we are celebrating this month, was a remarkable man. All of us are greatly indebted to him for what he did for the nation and for Lawrence Livermore National Laboratory. Teller had an enormous impact on physics and national security in the 20th century and was an inspiration for countless researchers here at the Laboratory and elsewhere.

Those of us who were privileged to work with Edward gained from his vast knowledge, creativity, deep insights, and enthusiasm for scientific discovery and its application. He had a way of always getting to the heart of a matter. Early in my nuclear design career, I was working on a new concept and got it on the test schedule. After the device went downhole, I began to worry about a potential problem. Several of us did a lot of calculations, which were inconclusive but indicated that the device would not perform as anticipated. I was advised to see Edward and walked in with a pile of computer simulation results. He waved them off and asked me to explain the problem. After about a minute, Edward stopped me and said, "There are three possibilities. If you are wrong about the effect of the flaw, you will be a hero because you will have demonstrated a new type of device. If you are correct about the flaw, you will be a hero because you correctly discerned a subtle effect that no one before thought of. The only way you can fail is to not try." He then dismissed me.

The article beginning on p. 4 celebrates Teller's life. His career can be divided roughly into two overlapping phases. The first, covering the period from 1928 to about 1952, was devoted to science research and university life. Teller had a superb command of virtually all aspects of physics, an insatiable curiosity, and a powerful desire to understand the universe. He made key contributions in a host of physics disciplines, including statistical mechanics, quantum theory, molecular physics, condensedmatter physics, surface physics, magnetism, nuclear physics, and astrophysics. The second phase of his life began with the discovery of fission in 1939. Over time, Teller's chief focus became the application of physics to defense and the cofounding of the nation's second nuclear weapons laboratory. He held a strong personal commitment to strengthening international security and an unshakable optimism that advances in technology could improve the human condition.

Key events leading to the establishment of our Laboratory occurred in 1951. While at Los Alamos, Teller made a singularly important technical contribution to nuclear weaponry with an insight that made thermonuclear weapons possible. He was a driving force behind the successful testing of the hydrogen bomb. However, he was dissatisfied with the progress of research and development in that area and argued in Washington that a second laboratory was needed. Through the efforts of Ernest O. Lawrence and Teller, the laboratory at Livermore was established in 1952, combining a multidisciplinary team approach to research and development with expertise in basic sciences and a goal to transform discoveries into applications that would benefit the nation.

For more than 50 years, Teller had a profound influence on Livermore, serving as a visionary scientific leader and Laboratory director, mentoring many colleagues, establishing an onsite applied-science branch of the University of California, and championing the importance of national defense. Two early examples in his Laboratory career set the stage for what Livermore would become. Teller recognized the importance of scientific computing and requested that the most advanced computer of the time, the Univac I, be ordered even before the Laboratory's official opening date. Today, we remain at the forefront of scientific computing. In the summer of 1956, Teller offered to deliver to the Navy, within five years, a compact strategic warhead for submarine-launched Polaris missiles. Fulfilling that promise required major breakthroughs, which established Livermore's reputation for risk-taking and applying innovative science and technology to address the nation's most pressing needs. We continue that legacy today.

Once, when asked about his personal legacy, Teller said, "Among the things I'm most happy to remember are Livermore's accomplishments, although I cannot accept praise or blame for them except in the very general sense that I did what I could to help bring the Laboratory into existence." Teller contributed far more than that to Livermore - and to the world. He has had a lasting influence on us all.

George H. Miller is director of Lawrence Livermore National Laboratory. 


\section{Edward Teller's Gentennial}

Bolobrating
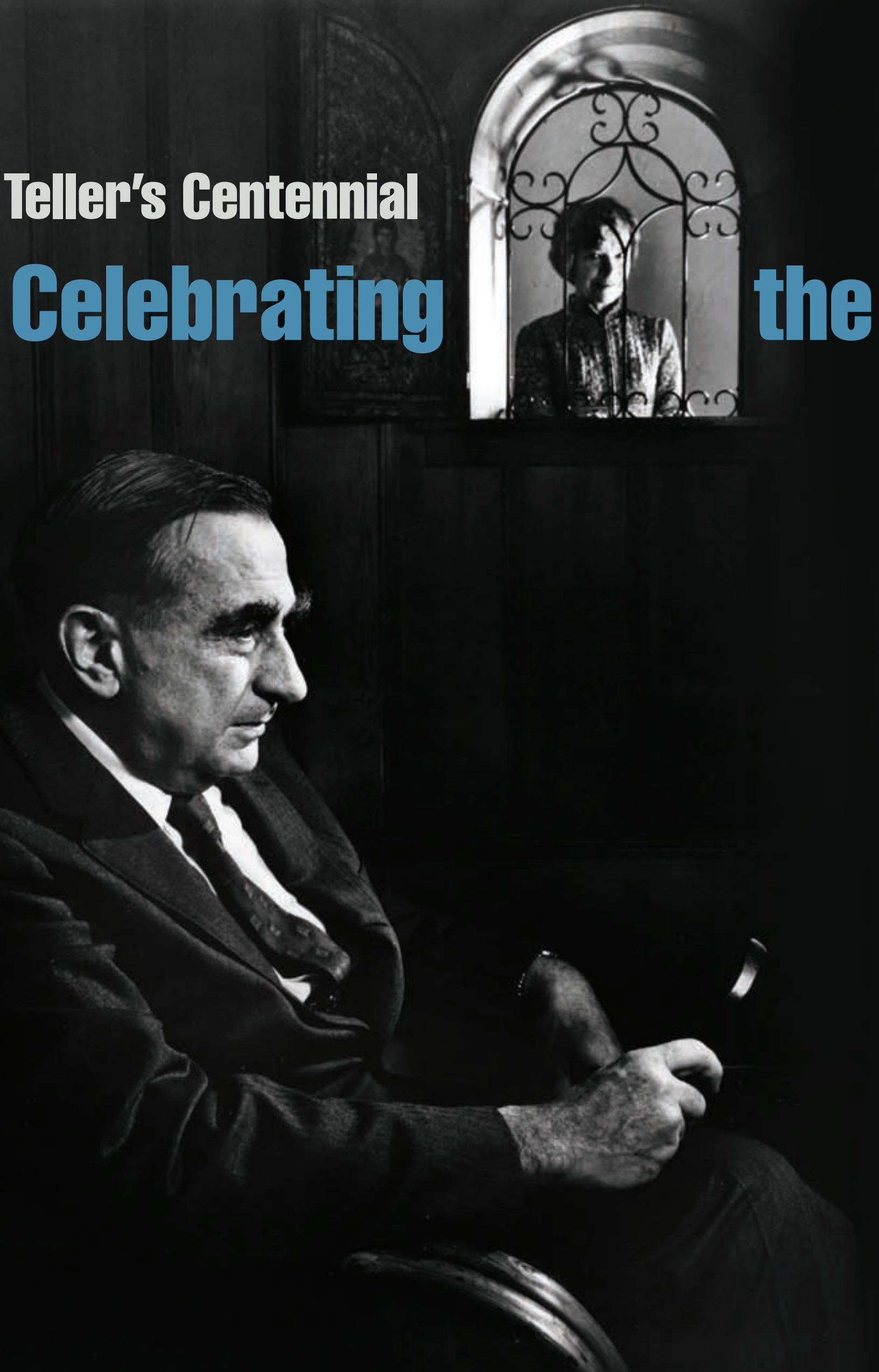


\section{Science and Technology}

Review's series of

articles tracing the

intellectual contributions

of Edward Teller, one of

Lawrence Livermore's

cofounders, concludes

with the remembrances

of his colleagues on the

centennial of Teller's

birth—January 15, 2008.

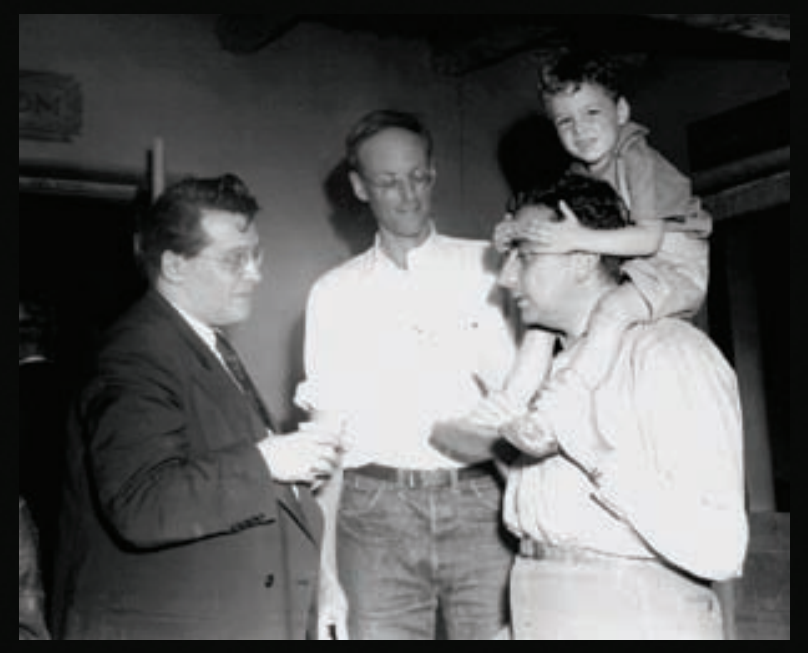

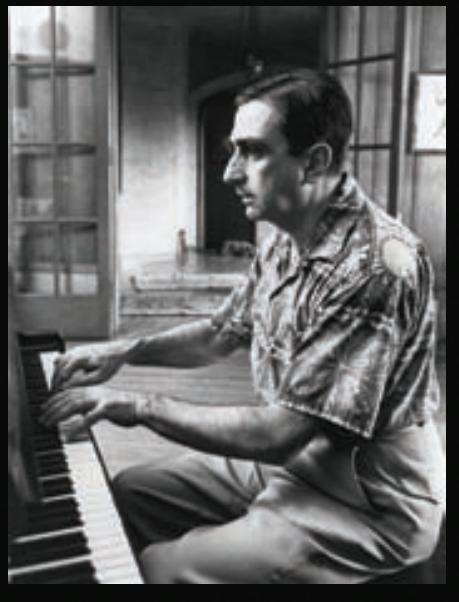

(Opposite page) A photographer captures Edward Teller at home in Palo Alto, California, while wife Mici looks on. (Left) Teller's son Paul receives an early introduction to science as Teller chats with famed physicists Julian Schwinger and David Inglis. (Above) Teller was an avid musician.
HYSICIST, visionary, patriot, cofounder of Lawrence Livermore, adviser to presidents, educator, musician, friend, colleague, husband, and father, Edward Teller deeply influenced the 20th century both in the scientific and policy arenas. Teller died September 9, 2003, at the age of 95 . This year marks the 100th anniversary of his birth, prompting the celebration and reflection of one of the giants of the Golden Age of Physics who was an inspiration for countless researchers.

"Teller was always pondering new ideas and approaches," says Livermore physicist Stephen Libby. "Many of his ideas changed science — and the world." Teller helped invent the weapons that played key roles in ending the Second World War and the Cold War. He was often far ahead of his time, for example, in his advocacy as early as the 1940s for advanced safeguards for nuclear power and in his innovative ideas on how to defend the Western world.
Teller was influential with presidents and members of Congress on issues of national security as well as science research and policy. Speaking at Teller's memorial service in 2003 at Lawrence Livermore, former Secretary of State George Shultz, a colleague of Teller's at Stanford University's Hoover Institution, spoke of Teller's influence in advising President Ronald Reagan and strengthening the president's resolve in negotiations that helped end the Cold War.

At the 1986 U.S.-Soviet summit in Reykjavik, Iceland, during intense negotiations with President Reagan, Soviet General Secretary Mikhail Gorbachev insisted that the U.S. drop its research in strategic defense. President Reagan hung tough, thanks in part to Teller's unflinching support of the Strategic Defense Initiative (SDI), which Teller helped to conceive. "Teller's role was crucial in impressing the Soviets of its potential reality," said 
Secretary Shultz. "That was a substantial contribution to the end of the Cold War." Also attending the Livermore service was Hungarian Ambassador András Simonyi who simply stated, "We owe him our freedom."

According to Livermore physicist Lowell Wood, Teller was a "mind warrior" because he fought the Cold War with his brain and not his body. "He persuaded a lot of people to do likewise," says Wood, who worked closely with Teller at the Laboratory. Another measure of Teller's influence can be seen in the indirect effect his ideas had on Soviet military and political leaders. In an effort to accelerate the pace of research and development of thermonuclear weapons, Teller campaigned for the establishment of a second U.S. nuclear design laboratory. Former Soviet officials acknowledged that the creation of Livermore to augment the efforts at Los Alamos convinced them that the Soviet

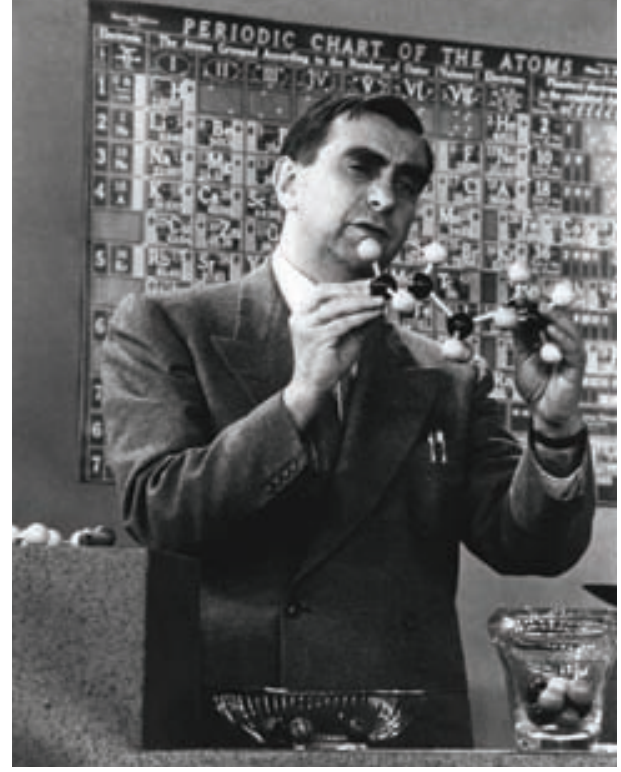

Teller's devotion to educating young people was legendary.

Union also needed a second nuclear design laboratory. That laboratory was created five years after Livermore opened.

Teller believed that strengthening national security was a personal obligation. Former Livermore physicist Edward Turano, now associate director of technology for the Defense Threat

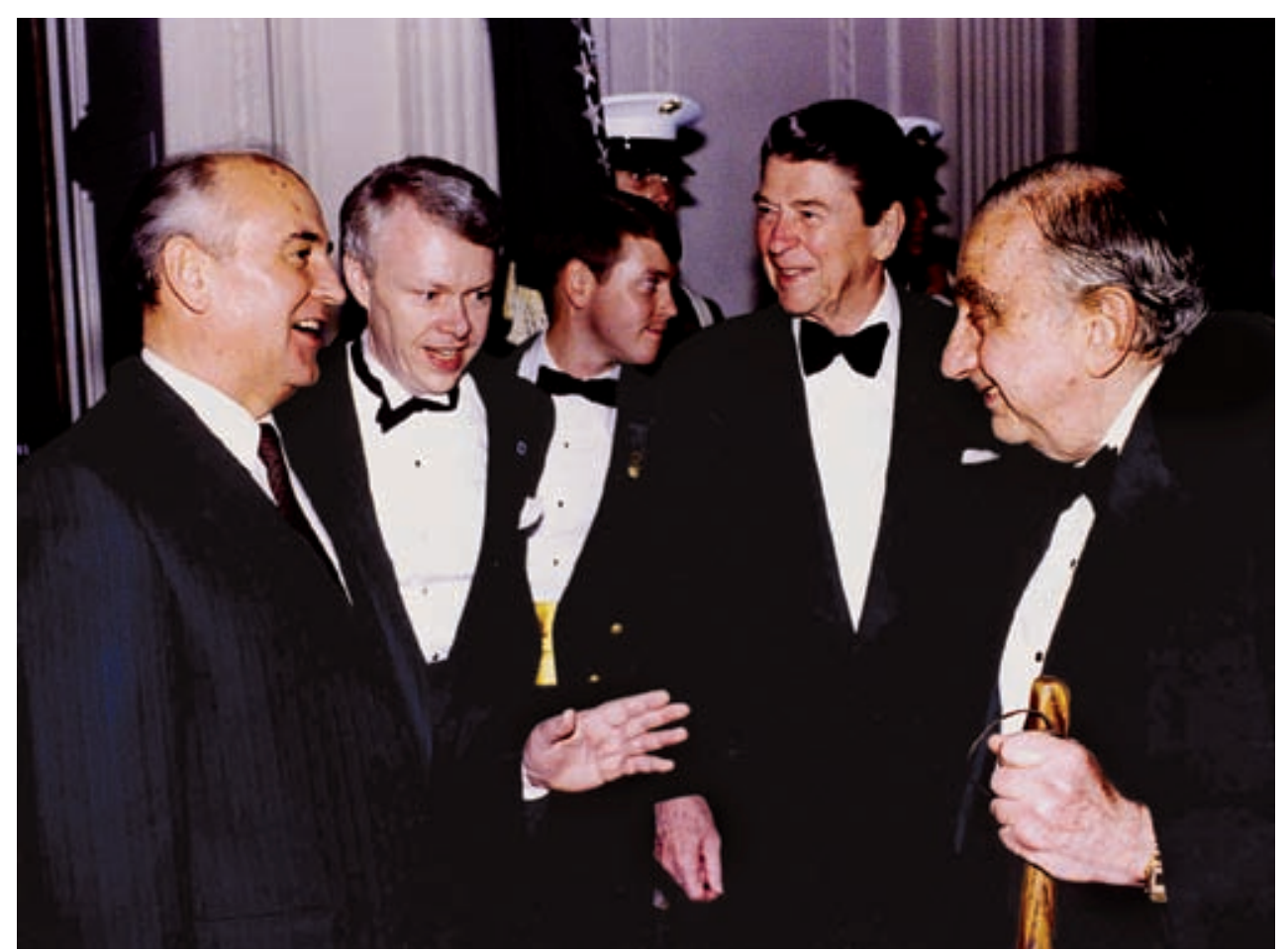

President Ronald Reagan introduces Teller to Soviet General Secretary Mikhail Gorbachev (far left) at a Washington, DC, reception.
Reduction Agency, says, "Teller was obsessed with finding favorable solutions for the advancement of humanity. He pondered how we could create and inspire new science and technology that could be used for good, while stressing the need for international coalitions. Teller and I would discuss how the proliferation of nuclear materials and technology was inevitable. He wanted to counter this threat by encouraging international safeguards and working toward worldwide collaborative concepts such as a global missile defense shield."

\section{Complete Understanding of Physics}

Several of Teller's major proposals were both politically and technologically controversial, but he was uncompromising in his beliefs and unconcerned about criticism of his ideas. However, in the scientific arena, Teller's former colleagues all agree on his broad knowledge of physics. "He had a mastery of physics," says Livermore physicist Neal Snyderman. "Edward sought to understand everything from a fundamental level."

Teller's approach to thinking through problems from fundamental principles went beyond basic science into the applied arena. "He was so much more than a theoretical physicist," says Laboratory Director Emeritus John Nuckolls. "A lot of people came to his office to think through their ideas with him. During a discussion, they would think they had come up with a convincing argument for their position, but the next morning, he would show up with a retort." Says Wood, "Edward could be ferocious on matters of intellectual combat."

Laboratory Director Emeritus Bruce Tarter recalls of Teller, "When one raised a question to him, he could give a 5- to 10-minute comprehensive, erudite answer that was astounding. He thought about physics all the time. Two of his defining drives in life were an insatiable intellectual curiosity and a powerful desire to understand the universe." 
Livermore physicist Mort Weiss recalls, "Teller had a wide range of interests and that made him a lot of fun. He was very open to new ideas. There was nothing small about him." Livermore physicist Berni Alder adds, "Teller was interested in so many things. He talked to everyone. When he smelled something interesting, he got involved. He always questioned people about their current work. He liked imaginative, creative, quick-thinking people. Teller didn't tolerate fools."

Teller once said, "Knowledge may be dangerous. Ignorance is incomparably more dangerous." Because he was always intensely curious in matters of science, Teller enjoyed discussing the latest scientific advances, especially in physics. "He would be interested in the fundamental aspects of a problem," says Wood. "If he could not find the bedrock in a problem, it was just a descriptive exercise, telling what it is, not why it is. By looking into the heart of a problem, he could tell someone what fundamental things were possible."

Teller had extremely high standards for what it meant to understand a topic, for example, particle physics. Snyderman explains, "He wrote papers with fellow giants of physics such as Enrico Fermi, Lev Landau, Richard Feynman, Julian Schwinger, and George Gamow that went straight to the heart of a problem." These renowned papers were more complete than most current published papers.

Wood recalls attending a presentation by Teller in 1959 while an undergraduate at the University of California (UC) at Los Angeles. Teller, who was the director of Livermore at the time, gave a technical seminar on the gravitational constant. His talk argued against the hypothesis that the gravitational constant had varied significantly since the birth of the universe - a hypothesis of Paul Dirac, one of the greatest physicists of the 20th century. In his lecture, Teller stated that if such variations had existed, the Sun would have been so luminous that the oceans would have likely boiled over during past epochs. However, fossil evidence shows life thrived. "His argument combined geology, astrophysics, biology, and paleontology," says Wood. "It was a staggering tour de force. He prepared his talk in his spare time, while he was leading the charge toward modern thermonuclear weapons. I remember thinking, 'Wow, this guy really knows physics.' I never forgot that seminar."

Teller's rare combination of deep knowledge and boundless imagination was evident even in his last years. (See the box below.) Less than two weeks before he died, Teller asked to see new data supporting an accelerating expansion of the universe. Three days before his death, Teller, Wood, and Nuckolls held a long discussion about advanced energy systems for the future.

\section{Impressive Record of Physics}

Teller's career can be divided roughly into two overlapping phases. The first, from 1928 to about 1952, was largely devoted to scientific research and university life. In the second phase, which began with the discovery of fission in 1939, he focused on applying physics to defense and, later, on cofounding the Laboratory with Ernest O. Lawrence.

During the first phase, which immediately followed the discovery of quantum mechanics, Teller made contributions to a host of physics

\section{Lunch with Edward}

Over the years, Edward Teller enjoyed having wide-ranging discussions over lunch with many scientists at Livermore. In his later years, participants included Brian Wilson, Stephen Libby, Neal Snyderman, Mort Weiss, Edward Turano, Todd Hoover, David Dearborn, Lowell Wood, Ralph Moir, Chuck Leith, John Nuckolls, and Richard More. No topics were set, and discussions lasted an hour or longer. Subjects centered around topics as diverse as fundamental physics, cosmology, mathematics, energy, nuclear proliferation, nuclear weapons projects, recent concepts in defense, politics, cancer, biology, and the human genome. Turano recalls, "Edward would ask, "What do we need to do now to be where we want to be 50 years from now?",

Typically, Teller started luncheon discussions with a topic that interested him at the moment, then asked his guests their opinions. Says Snyderman, "He was a social person and enjoyed learning through interactions with others. This characteristic may have stemmed from his friendship with Niels Bohr, who was very social." Although the discussions were often freewheeling, they also generated ideas that guests could exploit in their current national security work.

Even in the last year of his life, Teller's mind and memory appeared sharper than many scientists 30 years his junior. Because he could barely see, he might ask a lunch guest to read a paper to him, if required.

Snyderman says, "He was known as a stubborn person, but he was a physicist, so it was always possible to convince him with empirical evidence and coherent arguments. I enjoyed many long, lively conversations with him on a variety of topics in fundamental physics. I lost a very special friend."

Livermore physicist Lowell Wood was a long-time associate of Teller's. 
disciplines, including statistical mechanics, quantum theory, molecular physics, condensed-matter physics, surface physics, magnetism, nuclear physics, and astrophysics. (See the box below.) These contributions remain fundamental parts of current scientific knowledge and understanding.

Teller's early work on molecular physics provided insights to the dynamics of polyatomic molecules, thus deeply influencing subsequent development in the area of physical chemistry. Perhaps the most important part of this work was the discovery of the Jahn-Teller effect describing the distortion of nominally symmetric molecules. The Jahn-Teller effect is ubiquitous in chemical and solid-state physics.

Teller also proposed what became the basic adsorption model in surface physics, the Brunauer-Emmett-Teller equation of state, which accounts for the adsorbate atom's simultaneous tendencies to attach and evaporate. It is still applied in surface physics. In addition, the exactly solvable Ashkin-Teller model in statistical physics continues to provide insight into the thermodynamics of phase transitions. Teller was also a major contributor to the Monte Carlo computational method often called the Metropolis algorithm, which Computing in Science and Engineering selected as one of the 10 most important computational algorithms of the 20th century.

In 1936, Teller and Gamow made a key contribution to the rapidly developing field of nuclear physics in their paper on beta decay, which described how a nucleon could flip its spin during the decay transition when emitting an electron and an antineutrino.

This phenomenon is now called a GamowTeller transition, the discovery of which turned out to be a large step toward the modern Standard Model of elementary particles. The Teller-Gamow paper also unexpectedly led to an understanding of nuclear energy generation in the Sun.

In the late 1940s, with Fermi and Victor Weisskopf, Teller showed conclusively that the mu meson (or muon) could not be the then-sought Hideki Yukawa pi meson (or pion). In another contribution, the Lyddane-Sachs-Teller relation described the dielectric constant needed to explain how photons propagate in salts. This relation proved, in turn, to be a fruitful analogy, leading Maurice Goldhaber and Teller to predict strong universal gammaray absorption resonances in nuclei.

\section{Life at the Laboratory}

The second phase of Teller's career centered on work done for Lawrence Livermore. In 1951, while still at Los Alamos, Teller's revolutionary contribution to nuclear weaponry was his technical insight that made thermonuclear weapons possible and practical. He was the driving force behind the successful development and testing of the first hydrogen bomb. In 1952, Lawrence and Teller opened the Livermore branch of the University of California Radiation Laboratory (UCRL), and for more than five decades, Teller was a major influence for the extraordinary record of research and development at Livermore. "Teller and Lawrence were an unbeatable combination," reflects Wood.

At Livermore, Teller pushed for novel nuclear weapon designs and smaller warheads. In particular, in 1956, he proposed to the Navy the development of thermonuclear warheads small and light enough to be carried on submarine-launched ballistic missiles. That successful program, much of which was carried out while Teller served as
Science and Technology Review articles honoring Edward Teller's life and contributions to science.

From Sound Waves to Stars

Teller's Contributions to Shock Physics

March 2007

A Search for Patterns and Connections

Teller's Contributions to Computational and Mathematical Physics

April 2007

Exchanging Insights on Quantum Behavior

Teller's Contributions to Condensed-Matter Physics

May 2007

A Gifted Teacher of Applied and Fundamental Physics

Teller's Contributions to Education

June 2007

Taking on the Stars

Teller's Contributions to Plasma and Space Physics

July/August 2007

From Fission to Fusion and Beyond

Teller's Contributions to Applied Physics and Defense

September 2007

Back to Basics

Teller's Contributions to Atomic and Molecular Physics

October 2007

Probing Deep into the Nucleus

Teller's Contributions to Nuclear and Particle Physics

November 2007

Power to the People

Teller's Contributions to Nuclear Power Research

December 2007 
Laboratory director from 1958 to 1960 , established Livermore's reputation for innovative nuclear design. In 1998, Teller reflected, "The Laboratory is the one thing in my life that I am completely happy about."

In 1960, Teller accepted a joint appointment as professor of physics-atlarge for UC and as associate director for Lawrence Radiation Laboratory (both the Berkeley and Livermore sites). In 1965, he was named associate director for physics at Livermore. Upon his retirement in 1975 from UC, Teller became director emeritus at Lawrence Livermore and joined the Hoover Institution at Stanford University as a senior research fellow. At the Hoover Institution, he specialized in international and national policies concerning defense and energy.

In support of SDI during the 1980s, Teller promoted the concepts of $\mathrm{x}$-ray lasers driven by nuclear explosives and nonnuclear "brilliant pebbles" satellites. Even then, at an advanced age, he wanted to contribute to both science and his adopted homeland in any way possible. Above all, Teller believed that being a scientist meant solving the world's biggest problems.

\section{Focus on Applied Science}

Teller focused Livermore on applying basic science to national security issues. "He gets enormously big marks for pushing applied science," says Tarter. "He had an unshakable belief in technology to improve the human condition. He felt the Laboratory was a place where that could be carried out." Indeed, Teller recognized that U.S. security and prosperity depended on applied science and technology. According to Wood, Teller believed that the U.S. embraced applied science, unlike Europe, and credited this factor as being one that drove the U.S. to preeminence in the 20th century.

Teller's desire to see practical results from basic science research influenced his leadership of "Teller Tech," the Department of Applied Science at Livermore, which was established as part

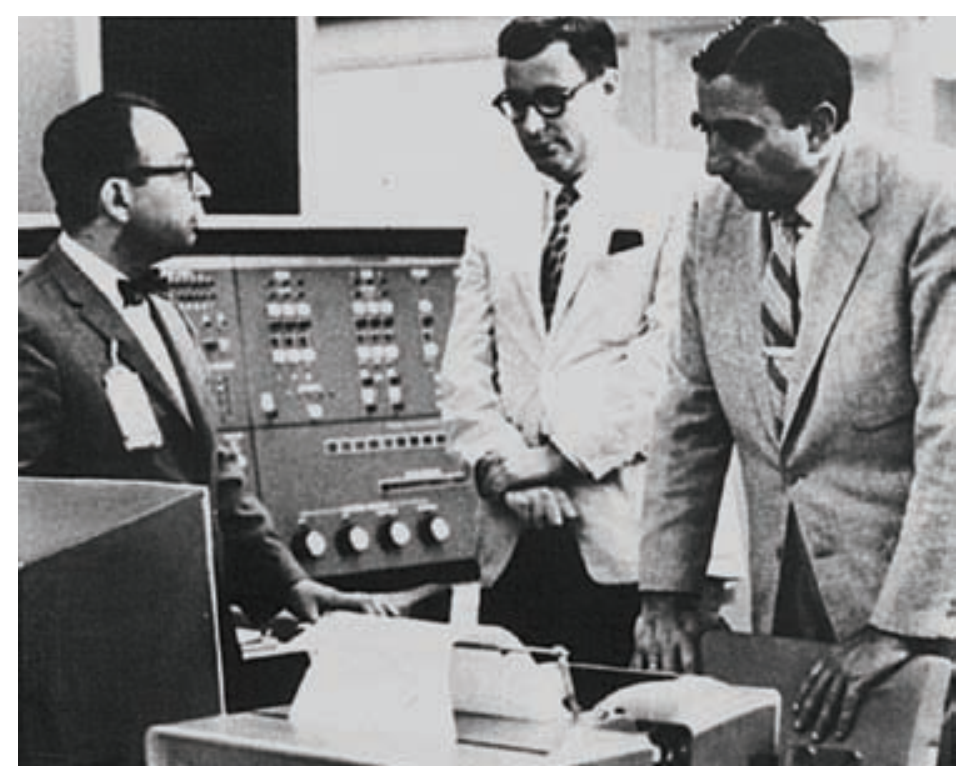

Teller was instrumental in acquiring Livermore's first generations of powerful computers. In this 1960 photograph, he confers with Sid Fernbach (left), who led scientific computing at the Laboratory, and Harold Brown, Teller's successor as Laboratory Director. The Livermore Advanced Research Computer is in the background.

of the College of Engineering at UC Davis in the early 1960s. His founding of Teller Tech was based on the idea of encouraging young applied scientists to take advantage of the latest developments in basic science.

Teller had always been inspired to teach. In the U.S., he taught successively at George Washington University, Columbia University, University of Chicago, and at several UC campuses, eventually holding the prestigious title of University of California Professor Emeritus. Many of his graduate students went on to become prominent scientists, including Chen Ning Yang from Chicago, who won the Nobel Prize in Physics in 1957. In 1963, at the height of the Cold War, Teller worked with Fannie and John Hertz to found the Hertz Foundation Graduate Fellowship Program to provide training for innovative applied scientists and engineers.

Teller considered the advancement of nuclear power one of the most important applications of science and engineering. In the late 1940s, he served as a member of the General Advisory Committee of the U.S. Atomic Energy Commission and chaired the Reactor Safeguard Committee. In his desire to make nuclear power plants safe, Teller identified operator error as the first problem to be solved, and he conceived the idea of burying reactors to avoid a catastrophic release of radiation. In the late 1950s, during the summer Teller spent at General Atomics in San Diego, he challenged Freeman Dyson, Frederic de Hoffmann, and others to design a small, ultrasafe research reactor. The General Atomics team succeeded with TRIGA ${ }^{\circledR}$.

During the last year of his life, when Teller was almost completely blind, he wrote a paper with Livermore physicist Ralph Moir on thorium-burning reactors sited underground. This reactor design would use molten salt technology either without reprocessing for proliferation resistance or with reprocessing to maximize resources. Teller argued for leaving the fission products stored underground at the reactor site indefinitely or, if required, eventually transporting them to a dedicated repository. This paper, his last, was published in 2005 in Nuclear Technology.

In applying science to issues of national importance, Teller tirelessly supported collaboration and openness. He believed advances in national security and research were stronger when conducted in the open. Teller was instrumental in the declassification of magnetic energy research. Nuckolls recalls that "Teller argued magnetic fusion had little, if anything, to do with weapons and was potentially a major force for good." 
One of Teller's great accomplishments at Livermore was promoting the use of computers to advance applied science. He was influenced by his long association with John von Neumann of the Institute for Advanced Study in Princeton, who helped pioneer the first electronic computers. Throughout its history, Livermore has been a world leader in using supercomputers and establishing

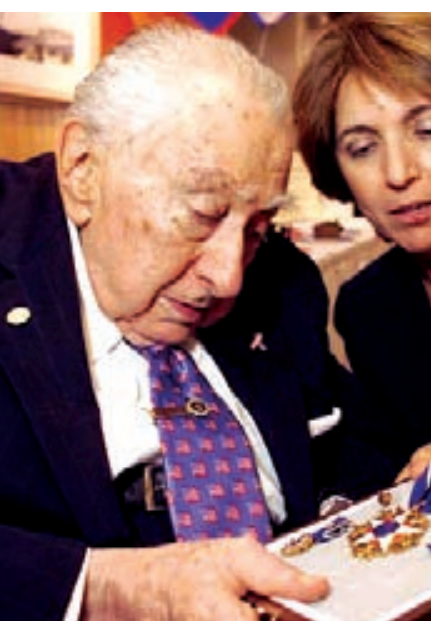

Teller and Livermore Director's Office administrator Shirley Petty admire Teller's Presidential Medal of Freedom.

Teller presided as grand marshal in several Livermore rodeo parades. simulation as a worthy partner with theory and experiment. In the 1950s and 1960s, however, computation in physics was not regarded as entirely respectable. "Real physicists worked with equations, not programs," says Livermore physicist Mal Kalos. "Teller understood better."

\section{Reflecting Teller's Style}

Libby observes, "The Laboratory has always reflected Teller's and Lawrence's styles: a place for innovation, imagination, and can-do attitudes. Livermore people have consistently focused on applications with a willingness to try new ideas and not be stopped by conventional thinking." Weiss adds, "We can't lose the spirit of inquiry that Teller brought.'

Perhaps the words of President George W. Bush, when he presented
Teller with the Presidential Medal of Freedom, best describe this giant of a man: "For a long life of brilliant achievement and patriotic service, America is in debt to Dr. Edward Teller." -Arnie Heller

Key Words: applied science, Ashkin-Teller model, basic science, Brunauer-EmmettTeller equation of state, Department of Applied Science University of California at Davis, Edward Teller, Gamow-Teller transition, hydrogen bomb, Jahn-Teller effect, Lyddane-Sachs-Teller relation, Metropolis Method, national defense, national security, nuclear power, physics, Presidential Medal of Freedom, Strategic Defense Initiative (SDI), thermonuclear weapon, $\mathrm{x}$-ray laser.

For further information contact Stephen B. Libby (925) 422-9785 (libby1@IInl.gov). 

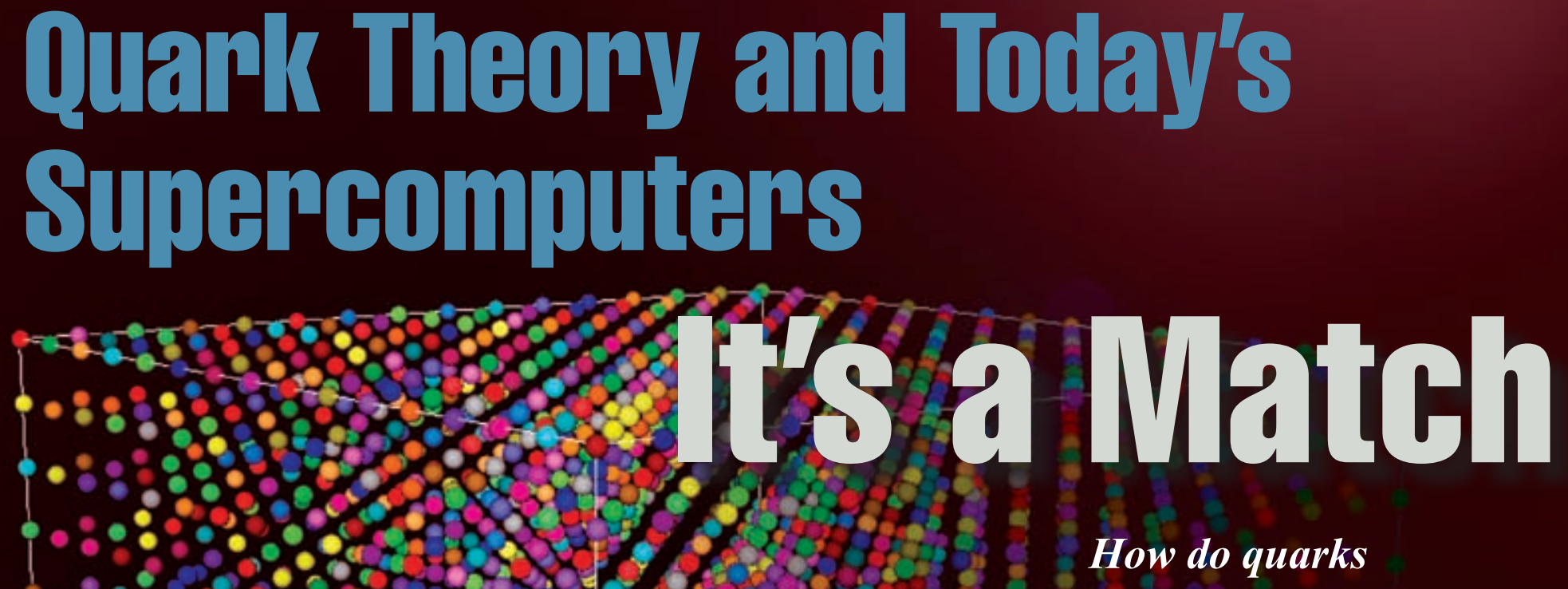

\section{behave? Quantum}

chromodynamics offers

the theory but requires

\section{enormous computing}

power to do the math.

A simulation captures the potential

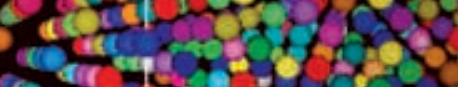

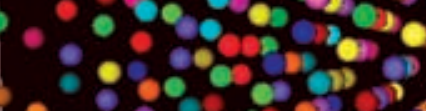

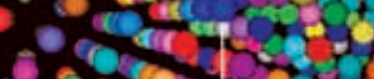

$32 \times 0$.

1.

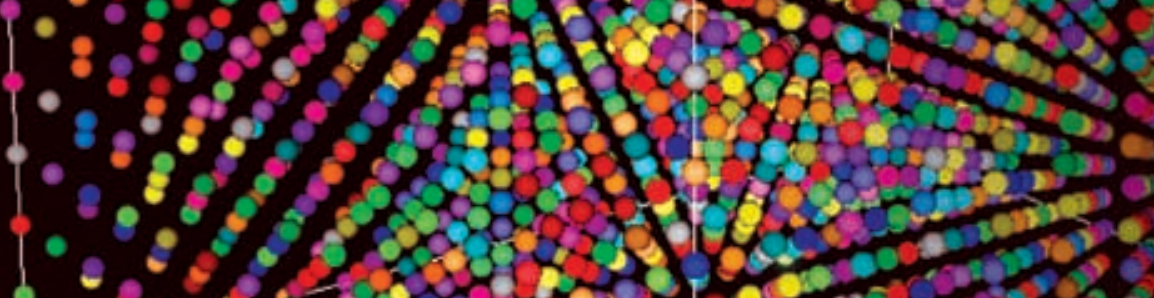

energy between two quarks, which

$0 \cos ^{2}$

make up protons and neutrons.
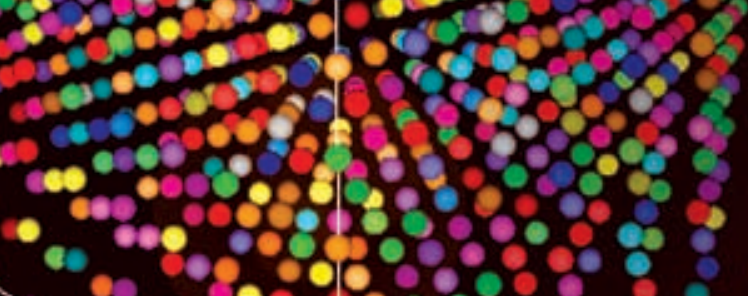
The experiments at Brookhaven, where gold ions were blasted apart into individual quarks, are the driver behind the computational effort to re-create the phase transition from quarks to larger particles. Some of the particles are common ones, such as neutrons and protons, and others are more exotic. Physicist Ron Soltz, who led Livermore's participation in the experiments at Brookhaven, says, "We succeeded in freeing the constituent quarks very briefly. However, what we observed after the experiment was not what we expected to see." Researchers thought they would find a hot, energized gas - or plasma - in which particles did not interact. Instead, they found strong particle interactions. "Our current models are only partially successful in explaining what we observed," says Soltz.

Livermore researchers working with theoretical physicists from around the world are using BlueGene/L to fill in the missing information about the phase transition. They are applying mathematics and the basic laws of physics to explain and extend results from the accelerator experiments at Brookhaven. Their calculations of the conditions surrounding the transition from quarks to larger particles are based on the theory of quantum chromodynamics (QCD). (See the box on p. 13.)

QCD was developed in the 1970s to explain how a vast array of particles could arise from only a few types of quarks, which are forever trapped inside. QCD describes the "strong force," whimsically termed color (chroma in Greek), that prevents quarks from running free except under extreme conditions. QCD has been called "the most perfect physical theory" by one its coinventors because of its broad scope and simplicity.

\section{The Match}

In the past, theoretical physicists have worked with pencil, paper, and their ingenuity to formulate new theories, such as relativity, string theory, and supersymmetry. However, in many cases, finding solutions to a theory's equations, such as calculating the strong force, is virtually impossible by hand. The complexities of QCD calculations, in fact, have been a motivating factor behind the design of supercomputers.

In the late 1970s, famed physicist Richard Feynman designed a network for an early supercomputer and used it for QCD calculations. QCD theoretical physicists at Columbia University in New York City have long had a close working relationship with supercomputer designers at IBM's nearby T. J. Watson Research Laboratory. QCD theorist Pavlos Vranas came to Livermore from IBM, where he was a member of the core architecture team for the Blue Gene line of supercomputers and lead designer of the Blue Gene network.

It is no coincidence, then, that a massively parallel computer is the ideal tool for simulating the interaction of quarks and other nuclear particles. BlueGene/L's processors communicate among themselves in much the same way that quarks and gluons interact in lattice QCD, the most accurate methodology for simulating the strong force. Lattice QCD defines space-time as a four-dimensional grid of points connected with links.

The 2006 Gordon Bell Prize for Special Achievement was awarded to the BlueGene/L supercomputer and quantum chromodynamics project team led by Vranas and Soltz. The team demonstrated the supercomputer's performance in a simulation that proved to be an ideal match between the demands of lattice QCD calculations with the computing capabilities of BlueGene/L. A version of lattice QCD written especially for BlueGene/L showed that the simulation scales almost perfectly. Lattice QCD can run on the full machine using all 131,072 processors, just as efficiently as it does using 1,024.

In a lattice QCD simulation, the lattice is broken into smaller pieces, or sublattices. "Each processor works on a sublattice, and the processors are connected by a network," says Vranas.
A lattice quantum chromodynamics (QCD) simulation shows when matter is heated to about 170 megaelectronvolts, or about 2 trillion degrees, it melts into a quark-gluon plasma. (a) Protons, neutrons, and other nuclear particles exist below the transition temperature. (b) When the transition occurs, (c) a hot plasma emerges full of quarks and gluons. Blue indicates confined quarks, and red indicates deconfined quarks. (a)

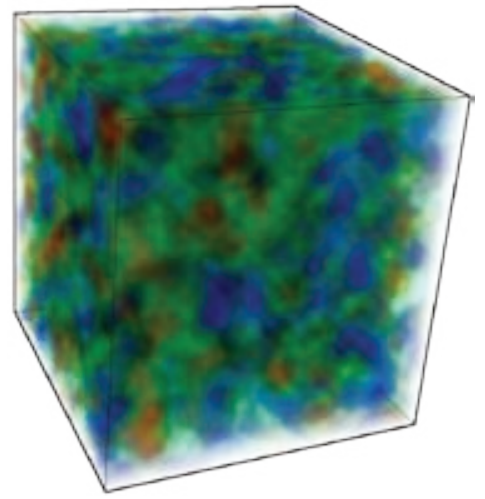

(b)

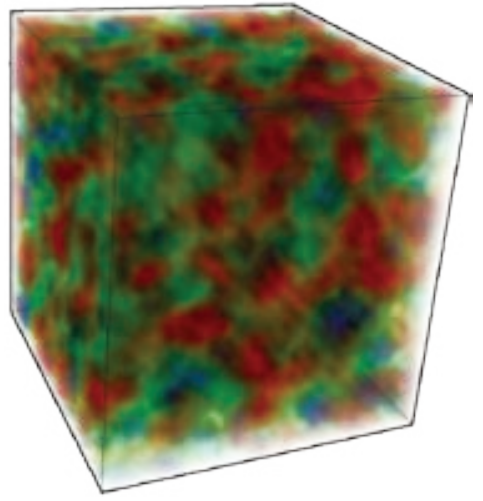

(c)

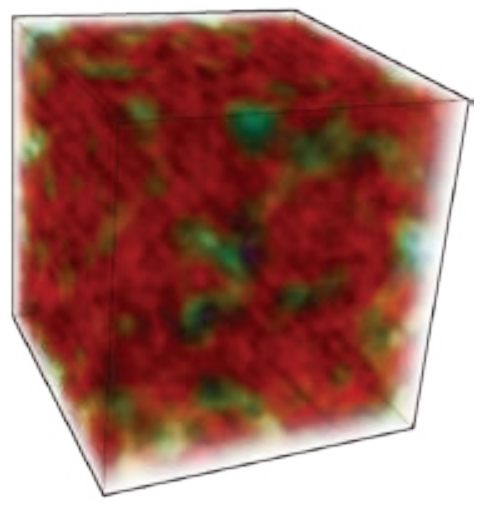


"For optimal operation, we needed to code the machine carefully." In October 2006, their coding produced a sustained operating speed of 70.4 trillion floatingpoint operations per second (teraflops), an extraordinarily fast performance.

Because BlueGene/L has many users, QCD researchers can routinely use only a percentage of its capacity. The typical simulation volume on BlueGene/L is equivalent to just a few proton diameters, or a few quadrillionths of a meter.

However, simulations using 10 percent of the machine's processors could reproduce essentially the full range of thermodynamic QCD behavior. "The QCD community is thrilled with the results that are possible today," says Soltz.

Thanks to BlueGene/L, Livermore has become the epicenter of QCD simulations. Soltz, an experimental physicist, is now a part-time theoretical physicist. He and theorists Vranas and Thomas Luu are participating in several collaborations that use BlueGene/L to simulate both the QCD physics that occurred at the time of the very hot big bang and the lowenergy QCD particle interactions in the cold universe of today. "BlueGene/L is the most important member of any QCD collaboration," says Soltz.

\section{A Lattice in Space}

Before lattice QCD was developed, QCD calculations depended on perturbative methods, which describe a complicated quantum system in terms of a solvable simple one. A weak disturbance added to the simple system perturbs it. The physical properties of the slightly more complex system can then be determined from equations that describe the behavior of small corrections to the known solutions.

Small perturbations can be calculated in studying a high-energy system, such as the quark-gluon plasma before the big bang. However, challenges arise in a lowerenergy system, for example just below the temperature at which quarks coalesced into larger particles. In this latter regime, the perturbations are too far from a known solution to be readily calculated. Lattice QCD, a nonperturbative method, has greatly facilitated the calculations by better simulating both high- and low-energy interactions.
QCD simulations model a box of finite space, defined by the dimensions of the lattice. The quarks live on the lattice points, and interactions occur along the grid lines between the points. When a continuum theory with continuous space-

\section{"The Most Perfect Physical Theory"}

Before the protons and neutrons that make up atoms, there were quarks. Quarks still exist, but now they are bound up in these and other larger particles. Six "flavors" of quarks - up, down, charm, strange, top, and bottom - make up almost everything in the visible universe. A proton, for example, is composed of two up quarks and one down quark. A neutron is made of two down quarks and one up quark. Up and down quarks are the least massive and most prevalent. More massive and more rare particles, such as kaons, hyperons, and charmed baryons, are composed of other quark combinations.

The various flavors of quarks also possess a type of charge, or quantum number, known as "color." Color is the source of the "strong force" that gluons carry, causing quarks to be confined in protons, neutrons, and other particles. While electromagnetism has two charges (positive and negative), the strong force has three charges (red, green, and blue). The strong force is responsible for the interactions of nuclear particles and is the basic ingredient of nuclear physics.

In the early 1970s, a team of scientists calculated how quarks are confined in larger particles. They showed that inside protons and neutrons, quarks behave almost as free particles, just as they did immediately after the big bang. This phenomenon of extremely weak interactions is known as asymptotic freedom. However, as the universe began to cool and expand, quarks moved apart, and the energy in their immediate vicinity declined. Nevertheless, the force between them did not diminish. Instead, as the distances between quarks increased, the force between them increased, pulling them together and confining them in larger particles. Pulling quarks apart requires a very large amount of energy that is eventually converted to mass through the creation of new quarks. These quarks quickly combine with the original quarks and form new nuclear particles. Hence, quarks are never seen in isolation.

The new theory of the strong force is called quantum chromodynamics (QCD): "quantum" because it describes subatomic particles that are governed by the laws of quantum mechanics, and "chromodynamics" because it describes the behavior of color, the source of the strong force. QCD explains why quarks only behave as completely free particles at extremely high temperatures and energies. In 2004, the three codiscoverers of asymptotic freedom and QCD as an explanation for the strong force received the Nobel Prize in Physics.

Frank Wilczek, a physicist at the Massachusetts Institute of Technology who shared the 2004 prize, has called QCD "the most perfect physical theory." Says Livermore physicist Pavlos Vranas, "Part of the theory's appeal is its broad scope. It applies to the smallest of particles as well as to cosmology, the science of the entire universe." QCD also requires very few parameters. Once the likelihood of finding quarks is determined for a particular energy scale, explaining a single nuclear particle of massless quarks requires just two pieces of information: the flavors and the colors. Most theories are much more complicated and require more information.

"However," says Vranas, "if we are modeling many quarks and how they interact for comparison with experimental results, we must include all of the exact physical information." Size, mass, temperature, and energy then become essential data. 
time is represented by a four-dimensional lattice, showing the quarks on the lattice is tricky. The traditional way of dealing with this so-called fermion doubling problem required using a lattice with a large number of lattice points. However, the necessary lattice size increased the amount of computing time beyond anything possible.
Ten years ago, Vranas performed the first numerical simulations that used a new method called domain-wall fermions, which introduced a fifth dimension to the lattice. The residual effects of resolving the doubling problem become smaller as the number of lattice points along the fifth dimension increase. Remarkably, this calculational

In this model, the interconnected geometry of BlueGene/L matches three of the dimensions used in lattice QCD. Lattice QCD also adds a fourth dimension, time, and often a fifth dimension-a calculating procedure. The fifth dimension increases the accuracy of simulation results and eases computing requirements. Researchers do not know whether this dimension corresponds to the physical world.
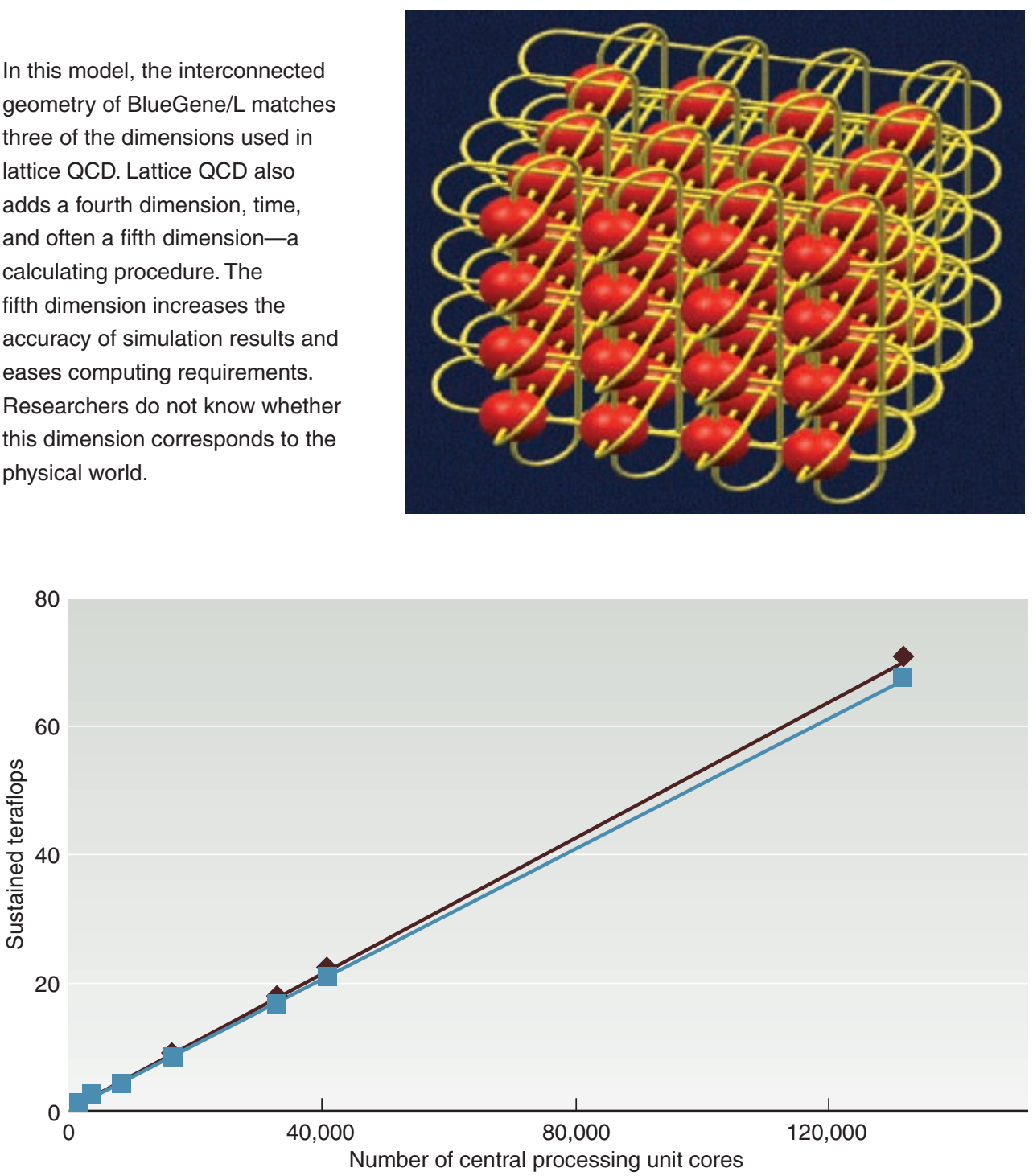

When Livermore researchers ran lattice QCD on the BlueGene/L system at Livermore, an algorithmic operator (brown) and its inverter (blue) scaled almost perfectly up to a sustained speed of 70.5 trillion floating-point operations per second (teraflops). The lattice was one of the largest ever to be implemented on a computer.

improvement is achieved with computing cost increasing only linearly as the lattice size increases.

\section{Hot and Cold Calculations}

A new collaboration called HotQCD, led by Soltz and Rajan Gupta of Los Alamos National Laboratory, is starting work from what is known about conditions inside the Relativistic Heavy-Ion Collider (RHIC) at Brookhaven. A wealth of data from the RHIC experiments provide compelling evidence of the creation, for a brief moment, of a hot quark-gluon plasma from larger particles such as protons and neutrons. However, no one knows the nature of the transition; how the gold ions were heated; what happened when neutrons and protons broke apart into quarks, gluons, and millions of other particles; or how quarks and gluons moved in the final hot plasma. The theoretical team's goal is to define the condition of the plasma when the phase transition occurred - that is, the plasma's temperature, pressure, and energy, or its equation of state. With the information from the RHIC experiments, which blasted larger particles apart into quarks and gluons, the team can "reverse engineer" the conditions of the big bang phase transition, which melted quarks and gluons into larger particles. Only with an accurate equation of state can the full hydrodynamics of the phase transition be modeled.

Simulations to date by the QCD community indicate that the transition occurred when the temperature of the universe dropped below 2 trillion degrees, or 170 million electronvolts (megaelectronvolts). A single electronvolt is a very small measure of energy, equal to 1 volt times the charge of a single electron. "We think we're accurate to within about 20 megaelectronvolts," says Soltz. "The HotQCD collaboration is trying to obtain greater accuracy, to within just a few megaelectronvolts."

Initial QCD equation-of-state calculations began in February 2007 using 10 percent of BlueGene/L. The 
HotQCD collaboration uses two methods to calculate the equation of state. The methods agree well, and the team's results show that errors related to a particular method are small. The team is also developing validation techniques for comparing simulations with experimental data from RHIC and from the Large Hadron Collider, the world's largest particle accelerator scheduled to come on line this year near Geneva, Switzerland.

Luu is applying lattice QCD to better understand the interactions of subatomic particles at low energies and temperatures. $\mathrm{He}$ is part of the Nuclear Physics with Lattice QCD collaboration, made up of nuclear physicists from around the world. This collaboration has produced the first predictions of scattering lengths for several combinations of particles, including pion-pion and pion-kaon. Scattering lengths are an indicator of the interactions occurring between the particles. These particles have a very short half-life and are difficult to measure experimentally before they disappear.

The collaboration is now focused on calculating the structure and interactions of the lightest nuclear particles - neutrons and protons, also called nucleons. "A lot of experimental data describe two nucleons," says Luu, "but no body of data exists for the interaction of three nucleons." Determining the scattering of these particles is more difficult because the signal-to-noise ratio in low-energy lattice QCD calculations is low. "We need larger calculations to get good data," says Luu. "BlueGene/L makes it possible."

Luu and his collaborators recently completed the first fully dynamic lattice QCD determination of the scattering of a nucleon and a hyperon, a more exotic particle. "This area is virgin territory," says Luu. "It's a fun wave to be on."

\section{Bigger Is Better}

As the capabilities of particle accelerators increase, scientists can delve deeper into nuclear particles. The smaller

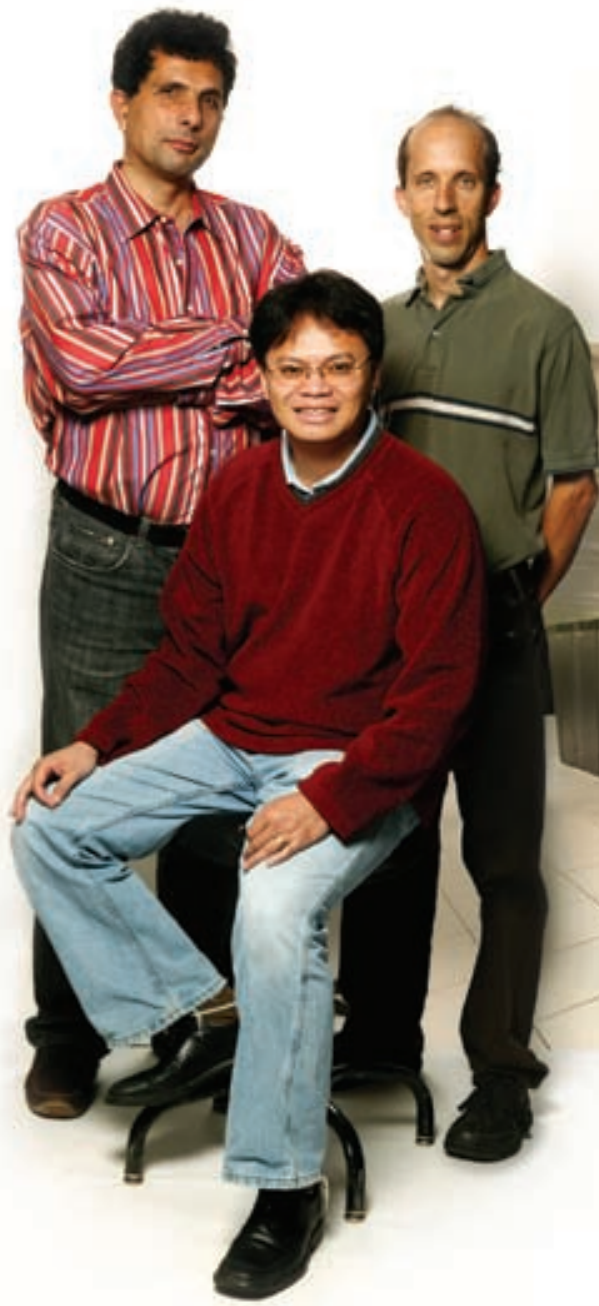

the object, the greater the energy needed to probe it. Individual atoms are released when molecules smash together with about 1,000 electronvolts (1 kiloelectronvolt) of energy. With 1,000 times more energy, individual nuclei become apparent. With another 1,000-fold increase of energy, revealing quarks is possible. The RHIC accelerator at Brookhaven can achieve

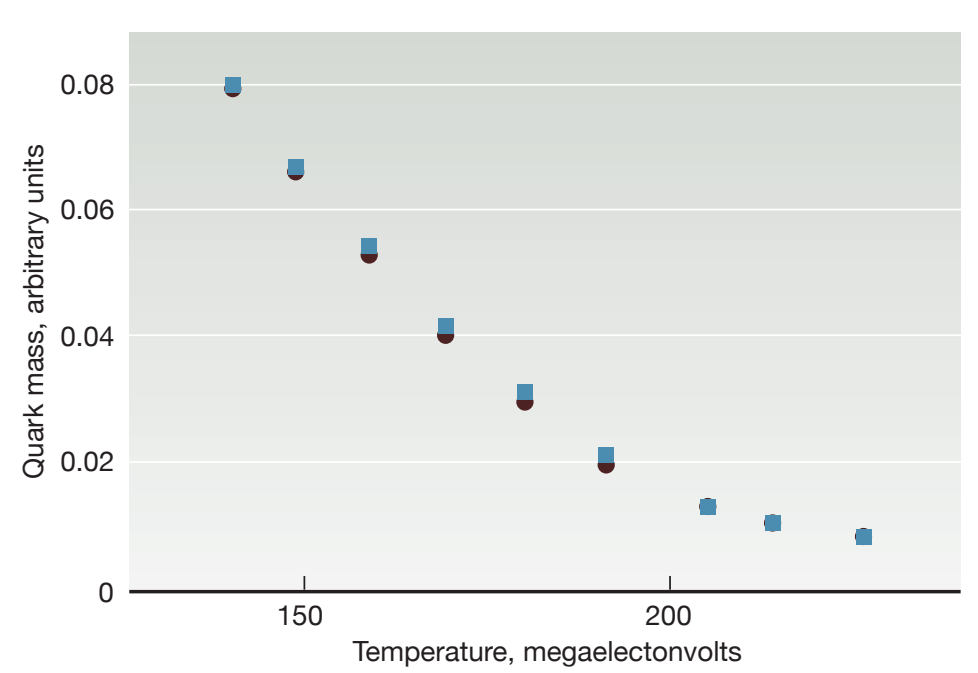

The HotQCD collaboration used two different methods to calculate the plasma's equation of state through the transition. Initial results show the two methods agree well. 
of almost 2 trillion electronvolts, or 2 teraelectronvolts. Fermilab is searching for the Higgs boson, a particle that theory predicts but has proved elusive experimentally. Later this year, the Large Hadron Collider's 27-kilometer circular accelerator will produce the highest energies yet, in the range of 14 teraelectronvolts. Who knows what strange and wonderful bits of matter this powerful machine will reveal?
Some speculate that the Large Hadron Collider may demonstrate a strongly interacting theory such as QCD but with a different number of colors and flavors and a host of entirely new particles. Because this new theory would be similar to QCD, lattice methods could be used for simulations using larger supercomputers, successors to BlueGene/L.

The need for more computing power is never-ending. Soltz, Vranas, and Luu

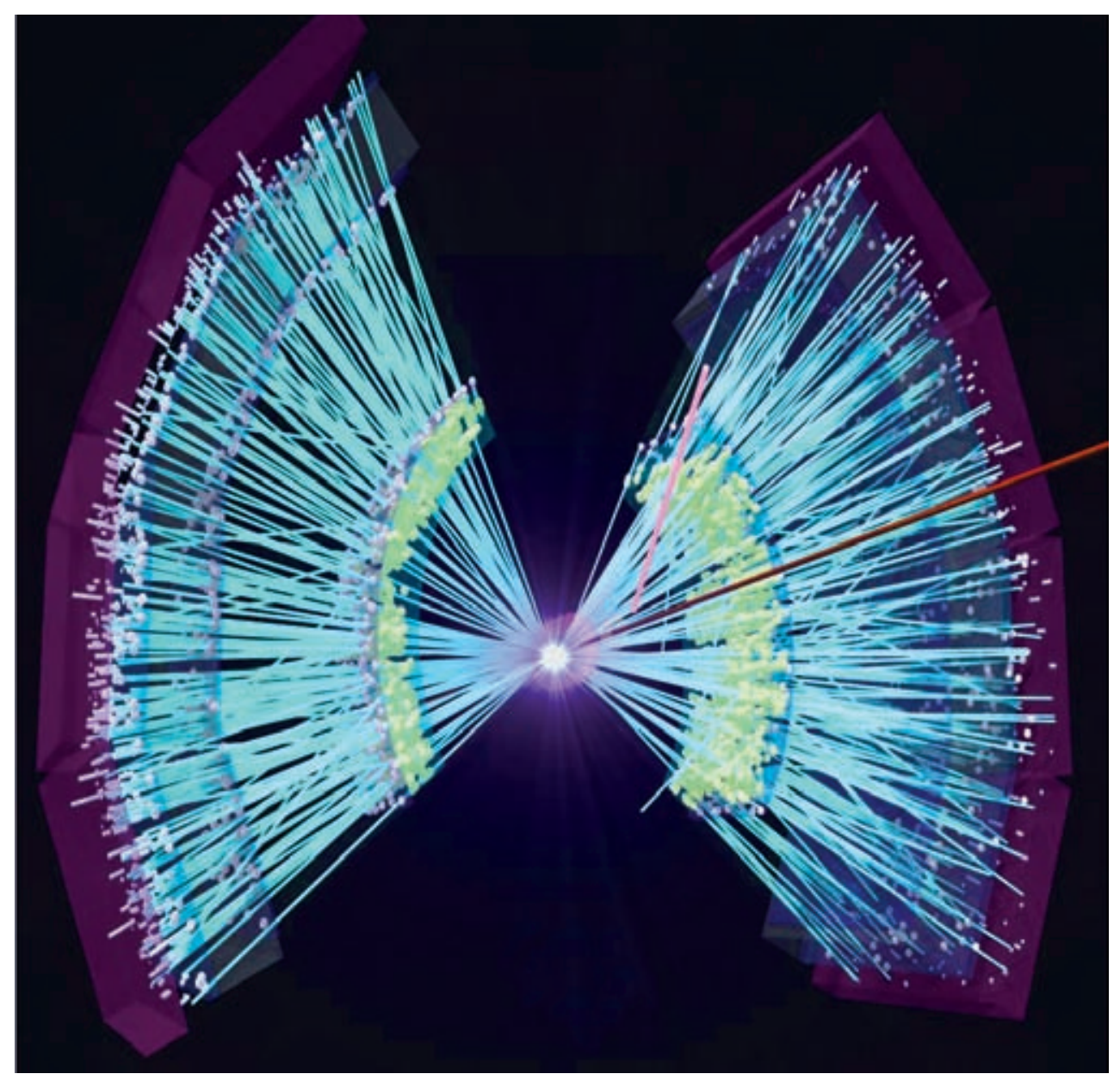

This simulation shows gold ions colliding inside the PHENIX detector at Brookhaven National Laboratory's Relativistic Heavy-Ion Collider in Upton, New York.

pounced when a competition call went out from Computing in Science and Engineering last year to describe what could be done with a quadrillion flops, or 1 petaflops, of computing power. The team's brief essay, "Simulating the Birth of the Universe on a Petaflop," explained the additional parameters and greater accuracy that more computing power would allow them to include in QCD simulations. Their winning essay appeared in the November-December 2007 issue of the magazine.

"Petaflops machines are not far away," says Vranas. "With bigger computers, we will be able to model bigger boxes of space with smaller lattice spacing. That means more accuracy. However, we will still be limited in the kinds of questions we can answer. Learning how the universe operates at the quantum level is important, and we will always need larger and more powerful computers for these explanations."

- Katie Walter

Key Words: big bang, BlueGene/L, Gordon Bell Prize, Large Hadron Collider, lattice quantum chromodynamics (QCD), quark-gluon plasma, Relativistic Heavy-Ion Collider (RHIC), strong force.

\section{For further information contact Ron Soltz} (925) 423-2647 (soltz1@IInl.gov). 


\section{The Role of Dentin in Tooth Fracture}

O UR parents and grandparents are among the first generations to reasonably expect to retain their teeth into old age. Improvements in diet and dental care over the past 50 years have reduced tooth loss from decay and gum disease. Today, a greater percentage of aged teeth fail from fracture. However, why older teeth break is unclear. Many scientists have suggested that restorative procedures, such as root canals or dental fillings, concentrate stress and make teeth vulnerable to fracture. Others have proposed that everyday tooth wearbrushing or grinding, for example-leaves cracks that later grow until a tooth fails.

A team of scientists from Lawrence Livermore and Lawrence Berkeley national laboratories and the University of California at San Francisco (UCSF) has observed that the hard tissue inside the tooth, called dentin, becomes brittle with age. Livermore physicist John Kinney, who is codirector of a multicampus project funded by the National Institutes of Health to study tooth fracture, says, "Embrittlement appears to occur as a natural aging process, even in the absence of decay or restorative procedures." Although the cause of this embrittlement is still unknown, recent evidence suggests that age-related changes at the molecular level may be responsible.

Sandwiched between the hard exterior cap of enamel and the central tooth chamber, dentin is the major structural component of the tooth. Softer than enamel, this tissue is part mineral (hydroxyapatite crystallites), part organic material (primarily collagen), and part fluid. At the microscopic level, dentin is a network of mineral and collagen through which tubes, called dentinal tubules, radiate outward from the central chamber to the enamel above. Surrounding each tubule is a mineral buildup called the cuff. These fluid-filled tubules measure just a couple of micrometers in diameter and are permeable, allowing them to transfer the sensation of hot or cold foods to the pulp nerves or trigger tooth pain.

\section{Understanding Dentin's Basic Behavior}

Traditional mechanical tests to measure the hardness and stiffness of dentin typically have resulted in large discrepancies among results, making it challenging for scientists to establish the tissue's basic mechanical behavior or to explore the effects of age on tooth strength. However, using a range of diagnostics at the Livermore and Berkeley laboratories, Kinney and his

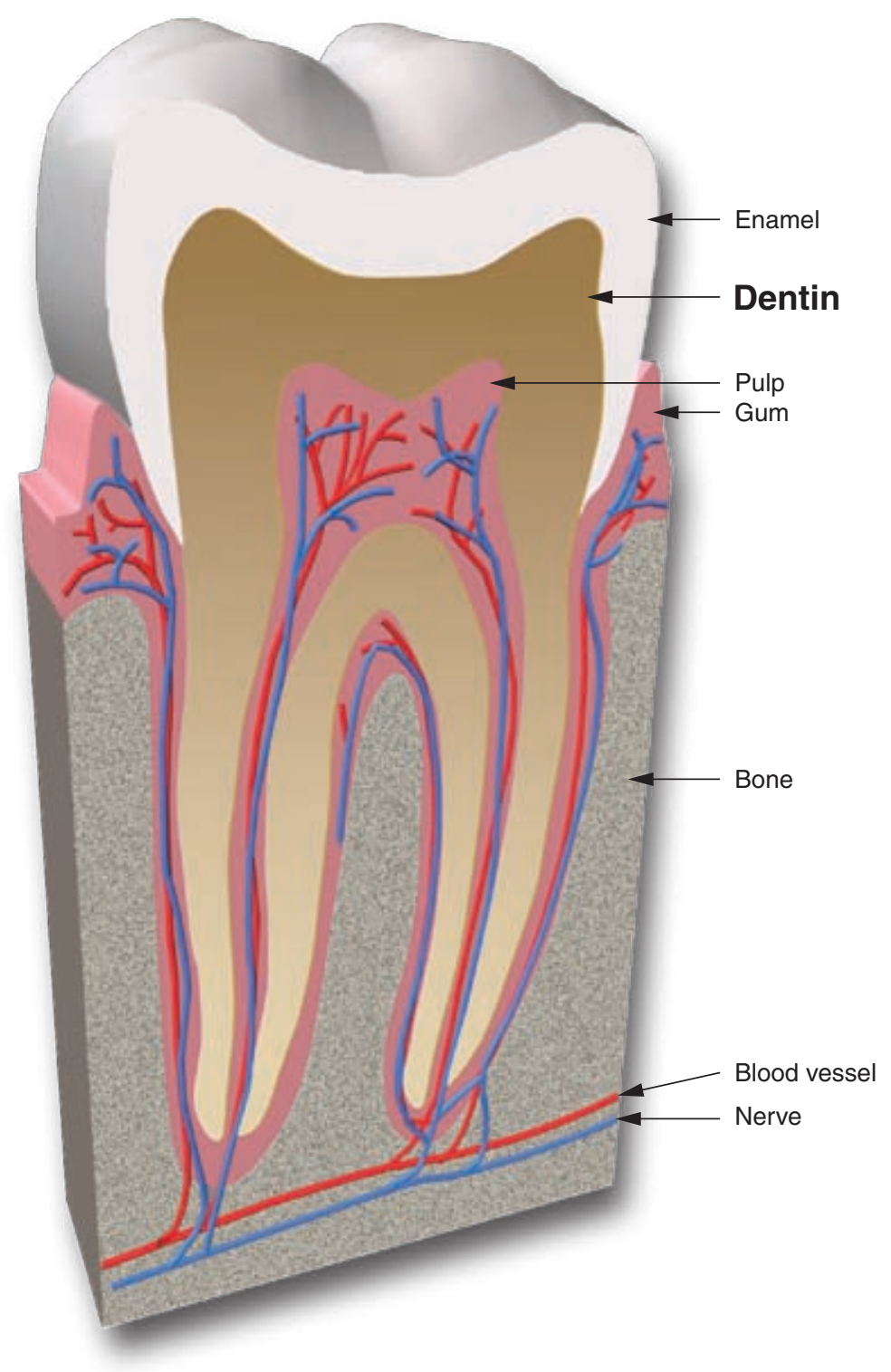

collaborators narrowed the uncertainties in dentin's mechanical properties.

According to Kinney, some of the biggest advances in developing a more precise picture of how teeth fail have been made through the collaborative work of Robert Ritchie's group at Lawrence Berkeley. Ritchie's group measured fracture toughness - the ability of a material containing a crack to resist fracture - in tooth specimens using mechanical techniques developed for research on ceramics and metals. The researchers initiated cracks in samples of dentin, put the samples under stress, and then watched the cracks grow using a scanning electron microscope (SEM).

The three-dimensional SEM images revealed that once a crack begins, some of the tubule cuffs near the advancing edge of the crack, known as the crack tip, develop cracks and relieve some stress. Uncracked "bridges" in the collagen network between the cracked cuffs act like steel rods in reinforced concrete. They hold the tooth together by limiting the crack opening and absorbing some of the applied load that would otherwise 
further crack propagation. Ritchie describes this behavior as an "extrinsic toughening mechanism similar to what is seen in many engineered materials."

The Berkeley group has also answered a long-standing question in dentin research - whether crack growth at low loads requires cyclic stressing (that is, alternating cycles of loading and unloading that mimic an activity such as chewing). Their research proved that cracks in dentin only grow if the load is cycled, a process known as fatigue. When dentin is held at constant stress, cracks become blunted, increasing the required stress for the crack to advance. Cycling the load permits the crack tip to alternately sharpen and blunt, advancing the crack.

\section{Properties Change with Age}

Thanks in large part to the team of Livermore, Berkeley, and UCSF researchers, the properties and microstructure of young, healthy dentin are now well understood and can be used as a baseline for characterizing how dentin ages. As teeth age, the tubules begin to fill with mineral deposits, starting at the root end and working upward. This phenomenon is known as transparency because the mineral deposits prevent the tubules from scattering light. As part of the National Institutes of Health study, Kinney's team focused on comparing the structure and micromechanical properties of younger dentin with older, more transparent dentin. This study required highly specialized analytical tools, including

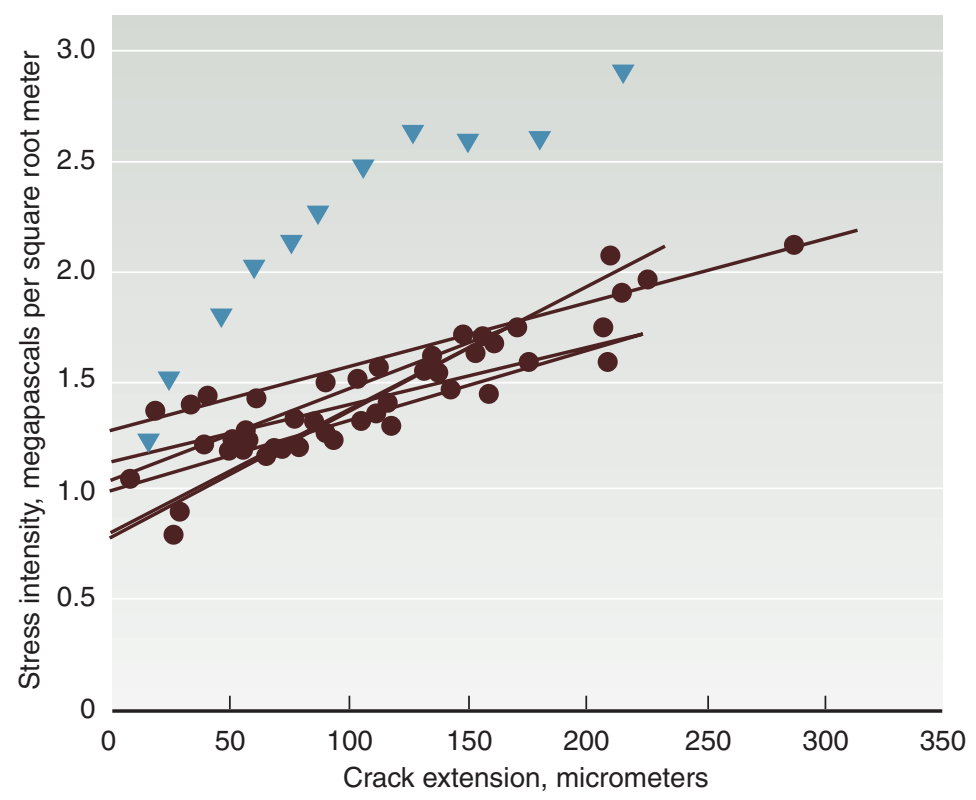

This graph captures the macroscopic-level behavior of young (blue) and aged (brown) dentin in fracture experiments. Once a crack was induced in dental tissue, higher levels of stress had to be exerted on the younger dentin than on the older dentin for the crack to grow. small-angle x-ray scattering at the Stanford Synchrotron Radiation Laboratory; resonant ultrasound spectroscopy and atomic force microscopy (AFM) at UCSF; and transmission electron microscopy at Lawrence Berkeley. The goal was to explore whether aging produced detectable changes in dentin's structure and properties.

The results of the aging study indicated that subtle changes occur in the size and shape of the mineral crystallites. However, no differences were observed in the elastic properties of young and old dentin measured with resonant ultrasound spectroscopy. These results were confirmed by nanoscale AFM indentation studies in the lab of Bill and Sally Marshall at UCSF. Initially, Kinney's team concluded that aged dentin was most likely as robust as young dentin. However, results from fracture studies at Lawrence Berkeley indicated that this early view was too optimistic.

Mechanical studies showed that older dentin has distinctive fracture and fatigue behavior. Of greatest significance was the finding that dentin becomes brittle with age. When young dentin is stressed, it visibly yields and deforms prior to breaking. However, the collaborators found older dentin does not yield before failing. At a microscopic level, older teeth appear to form far fewer microcracks in front of a crack. As a result, less of the strain energy is relieved, and virtually no bridges are produced. Fracture toughness in aged dentin measured about 20 percent lower than in young dentin. (See the figure on p. 19.) The team also studied how likely teeth were to crack from repeated stress and found that older dentin displayed a lower fatigue resistance, especially when subjected to higher stresses.

The culprit for increased brittleness in older dentin initially appeared to be the tubules, which, when filled, become stiffer. However, the team found that aged dentin does not create stress-relieving microcracks and bridges, regardless of whether the nearby tubules are open or plugged. Based on observations of fracture behavior on both visible and microscopic scales, further research advances require study at the molecular level to understand what is causing age-related dentin embrittlement.

Current research at the molecular scale is focused on the mineralized collagen network, the component of dentin that provides teeth with elasticity and strength. Recent work by Kurt Koester, one of Ritchie's graduate students, indicates that cracktip blunting, known to occur in young dentin, is greatly reduced or absent in aged dentin. Crack-tip blunting requires molecular motion in the collagen, so the fact that aged dentin does not experience blunting indicates something in the aging process is affecting collagen mobility. Kinney says, "At that tiny scale, we observed the robust tissue turning into a brittle substance as it aged." He suspects that either the collagen molecules increase in cross-linking density or dry out as the collagen ages, or the mineral nanocrystals in the collagen change in their shape, size, or orientation over time and somehow prevent the collagen from 

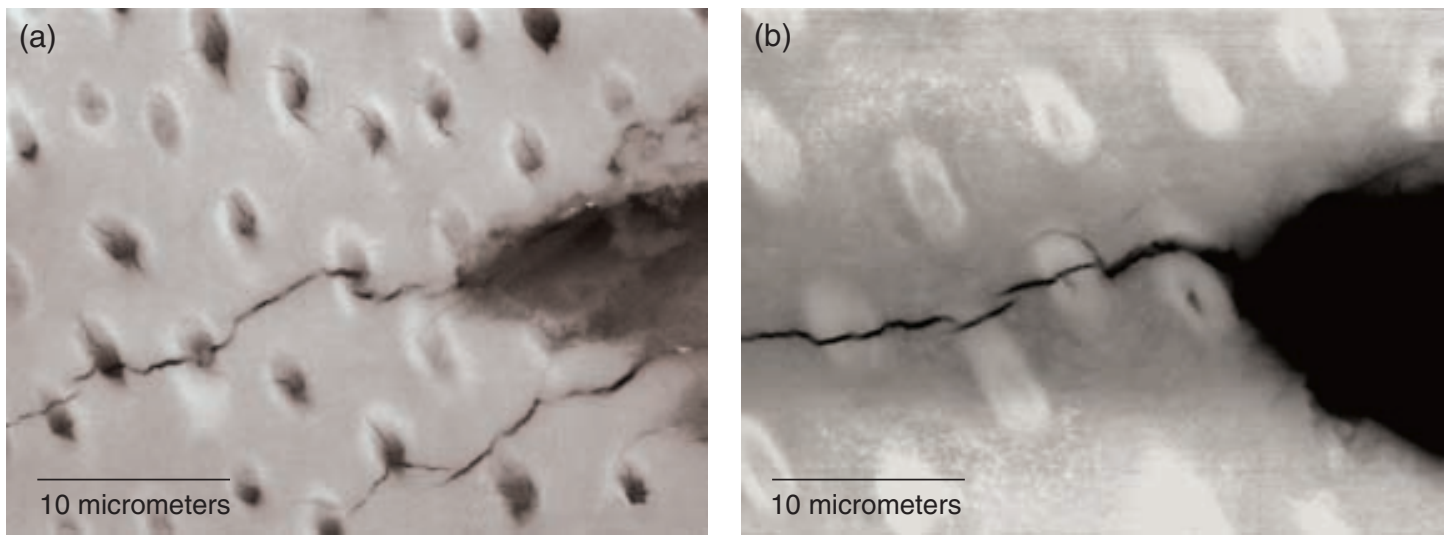

Scanning electron microscope images show how in (a) young dentin, the dentinal tubules form microcracks in response to an approaching crack, relieving some of the stress that would otherwise contribute to crack propagation. (b) Aged dentin has more mineralization in the tubules and a brittle intertubule network of collagen, so it does not form as many microcracks or inhibit the crack's progress.

moving. Either process, or both processes, could be causing the crack tip to remain sharp in aging dentin.

\section{Future Investigations}

Although evidence is mounting that age-related changes on a nanometer scale may lead to the deterioration of fracture properties of the tooth as a whole, more research is necessary to determine precisely what is happening. To date, physical measurements made of dentin's mechanical properties have been limited to the tissue's response across multiple length scales. The team plans to narrow its focus by using small-angle $\mathrm{x}$-ray scattering to measure the strain in individual collagen fibers and the size and orientation of nanocrystals in young and aged dentin. Because fillings, crowns, bridges, and other dental repairs must bond to dentin, "knowing more precisely how dentin changes with age will also help advance restorative dentistry treatment methods," says Sally Marshall.

For Kinney, an important outcome of the dentin studies is the insight it brings to his bone fracture investigations. (See $S \& T R$,
September 2006, pp. 20-22.) Because dentin is nearly identical in composition to bone on the nanoscale, the study of aged teeth may reveal why aging bones often become fragile.

Using techniques traditionally applied to study engineering materials, researchers are approaching a better understanding of difficult-to-study biological materials on several scales. Although stopping the effects of time may be impossible, the studies on dentin, and aging tissue in general, may increase awareness on the effects of aging and improve treatment for both tooth and bone disease.

-Rose Hansen

Key Words: atomic force microscopy (AFM), collagen, dentin, dentinal tubules, fracture toughness, resonant ultrasound spectroscopy, scanning electron microscope (SEM), transmission electron microscopy.

For further information contact John Kinney (925) 422-6669 (jhkinney@pacbell.net). 


\section{Patents}

System and Method for Characterizing, Synthesizing, and/or Canceling Out Acoustic Signals from Inanimate Sound Sources John F. Holzrichter, Greg C. Burnett, Lawrence C. Ng U.S. Patent $7,283,948$ B2

October 16, 2007

This system and method for characterizing, synthesizing, or canceling out acoustic signals from inanimate sound sources consists of propagating wave electromagnetic sensors that monitor excitation sources in soundproducing systems such as machines or musical instruments. Acoustic output is also monitored. A transfer function characterizing the soundproducing system is generated from such information. The transfer function allows acoustic output to be synthesized or calculated. The method enables accurate calculations of matched transfer functions relating to specific acoustic outputs. Knowledge of these signals and functions can be used in sound replication, sound-source identification, and sound cancellation.
Real-Time Method and Computer System for Identifying Radioactive Materials from HPGe Gamma-Ray Spectroscopy

Mark S. Rowland, Douglas E. Howard, James L. Wong, James L. Jessup, Greg M. Bianchini, Wayne O. Miller U.S. Patent $7,285,784$ B2

October 23, 2007

This real-time method and computer system identifies radioactive materials by collecting gamma count rates from a high-purity germanium (HPGe) gamma-radiation detector and referencing them against a library of nuclear-material definitions. Each definition is associated with a nuclide or isotope material and has at least one logic condition associated with a spectral parameter of a gamma-ray energy spectrum. The method determines whether the spectral parameters satisfy all logic conditions for any one of the library definitions, and subsequently uniquely identifies the material, if it is a nuclide or isotope material associated with a library definition. The spectrum and identification are updated in real time.

\section{Awards}

Tomás Díaz de la Rubia, associate director for the Chemistry, Materials, Earth, and Life Sciences Directorate, has been named a Fellow of the American Association for the Advancement of Science. He is among 471 new fellows recognized by the association in 2007 for their scientifically or socially distinguished efforts to advance science or its applications.

Díaz de la Rubia was elected to the physics category for his distinguished contributions to computational materials science and radiation damage to materials. He joined Lawrence Livermore in 1989 as a postdoctoral researcher and became a full-time staff member in 1994. As group leader for Computational Materials Science, he helped build an internationally recognized effort in computational materials science at Livermore. From 2000 to 2002, he led a program for the National Ignition Facility, focusing on optical materials and target development, until he moved into the associate director role in 2002. Díaz de la Rubia's recent scientific research has focused on using large-scale computer simulations to investigate the diffusion, defects, and microstructural evolution of materials in extreme environments.

On October 12, 2007, the Norwegian Nobel Committee announced the $\mathbf{2 0 0 7}$ Nobel Peace Prize will be shared between the Intergovernmental Panel on Climate Change (IPCC) and former Vice President Al Gore. The award recognizes the recipients' efforts to build and disseminate knowledge of human-induced climate change and to lay the foundations for the measures needed to counteract such change. More than 40 Lawrence Livermore employees made key scientific contributions to the IPCC assessment reports that address anthropogenic climate change.
The Laboratory's Program for Climate Model Diagnosis and Intercomparison (PCMDI) is funded by the Climate Change Research Division of the U.S. Department of Energy's Office of Science, Biological, and Environmental Research. PCMDI has provided information for the IPCC reports since 1990. In 1996, as part of the IPCC's Second Assessment Report, Livermore research on climate fingerprinting contributed to the historic conclusion that "the balance of evidence suggests a discernible human influence on global climate." The research also supported subsequent IPCC findings. The acknowledgments of the Fourth Assessment Report recognized PCMDI for its valuable role in archiving and distributing climate model output. In addition, IPCC publicly honored PCMDI with a plaque commemorating its significant contributions to that report.

Hundreds of worldwide authors, who are experts in their field, devoted time and labor to writing and reviewing the IPCC reports. Livermore participants included Krishna AchutaRao, Jenny Aquilino, Cyndi Atherton, Dave Bader, Govindasamy Bala, Celine Bonfils, Jim Boyle, Ken Caldeira, Cathy Chuang, Curt Covey, Jane Dignon, Charles Doutriaux, Bob Drach, Philip Duffy, Hugh Elsasser, Mike Fiorino, Larry Gates, Peter Gleckler, Allen Grossman, Stan Grotch, Tony Hoang, Stephen Klein, Mike MacCracken, Norm Miller, Joyce Penner, Tom Phillips, Jerry Potter, Benjamin Santer, Bob Schock, Ken Sperber, Karl Taylor, Starlyne Thompson, Michael Wehner, Dean Williams, and Don Wuebbles. 


\section{Edward Teller's Century: Celebrating the Man and His Vision}

Lawrence Livermore cofounder Edward Teller deeply influenced the 20th century in the scientific and policy arenas. Teller died September 9, 2003, at the age of 95. This year marks the 100th anniversary of his birth. Teller was influential with presidents and members of Congress on issues of national security, science research, and policy. He had a deep and complete understanding of all aspects of physics. He contributed to statistical mechanics, quantum theory, molecular physics, condensedmatter physics, surface physics, magnetism, nuclear physics, and astrophysics. He wrote papers with fellow giants of physics such as Enrico Fermi, Lev Landau, Richard Feynman, Julian Schwinger, and George Gamow. For more than five decades, Teller was a major driving force behind the extraordinary record of research at Livermore.

Contact: Stephen B. Libby (925) 422-9785 (libby1@IInl.gov).

\section{Quark Theory and Today's Supercomputers: It's a Match}

Livermore has become a center for theoretical advances in particle physics, thanks to the presence of BlueGene/L, the world's most powerful computer. Quantum chromodynamics (QCD) theory explains the behavior of nuclear particles and their constituent quarks. Lattice QCD, the primary tool for simulating QCD, requires as much computing power as possible for accurate calculations. Those needs match almost perfectly with the capabilities of BlueGene/L. A team led by two Livermore theoretical physicists won the 2006 Gordon Bell Prize for Special Achievement in demonstrating this match running all of the machine's processors. Livermore researchers and theoretical physicists worldwide are using BlueGene/L to explain and extend results from accelerator experiments at Brookhaven National Laboratory. In these experiments, gold ions were melted into their constituent quarks, and new particles were created. However, particle interactions in the plasma were greater than current models had predicted. Simulations using lattice QCD on BlueGene/L are providing data on the plasma's equation of state through the transition from larger particles to quarks, answering questions the experiments could not.

Contact: Ron Soltz (925) 423-2647 (soltz1@IInl.gov).

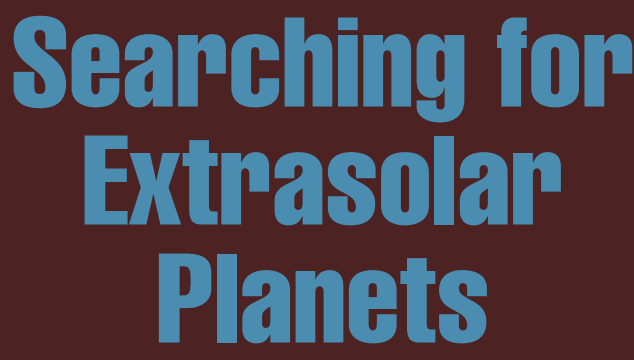

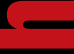

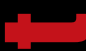

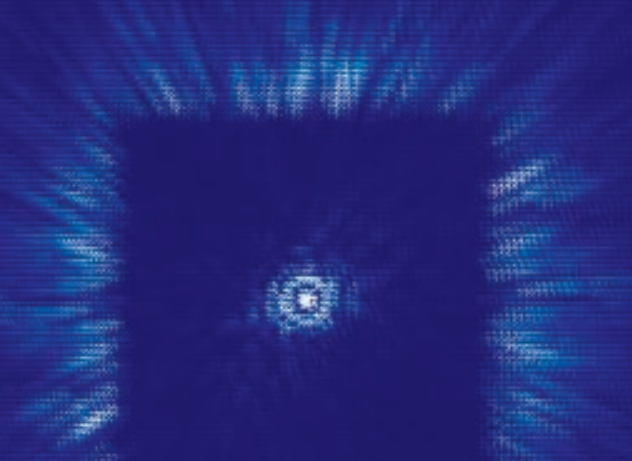

The Gemini Planet Imager will detect faint distant planets not now visible from Earth.

\section{Also in March}

- Animation techniques help scientists and engineers effectively communicate their ideas and research in visually compelling ways.

- Livermore physicists are exploring the electrical properties of diamondoids, tiny molecules of diamond.

- The Laboratory's EBeam 20/20 Profiler standardizes electron-beam welding and improves quality control. 
Science \& Technology Review

Lawrence Livermore National Laboratory

P.O. Box 808, L-664

Livermore, California 94551
PRSRT STD

U.S. POSTAGE

PAID

LIVERMORE, CA

PERMIT NO. 154 